\title{
Orthometallation as a strategy in Pd-mediated organic synthesis
}

David Aguilar, Luciano Cuesta, Sonia Nieto, Elena Serrano, Esteban P. Urriolabeitia*

Departamento de Compuestos Organometálicos, Instituto de Ciencia de Materiales de Aragón, CSIC-Universidad de Zaragoza, 50009 Zaragoza (Spain)

*Dr. Esteban P. Urriolabeitia (corresponding author): CSIC-Universidad de Zaragoza, Pedro Cerbuna 12, 50009 Zaragoza (Spain). E-mail: esteban@unizar.es

\begin{abstract}
The orthopalladated complexes are among the most representative Pd(II) compounds. They display a wide prospect of applications, but they are mainly known by their use as intermediates in metal-mediated organic synthesis. In this review we describe how palladacycles are used to build up new molecules through regioselective formation of C-halogen, C-O, C-N, C-P, C-S and C-C bonds, either under catalytic or stoichiometric conditions. This methodology is based on the selective incorporation of the Pd into the organic skeleton to be modified and subsequent reactivity of the Pd-C bond toward different substrates. In many cases this strategy is alternative or even competitive, improving standard organic methods. The most recent achievements of the last five years will be covered here, presenting only the most impressive results.
\end{abstract}




\section{1.- INTRODUCTION}

During the past half century, transition-metal organometallic compounds have undergone an impressive growth as subjects for research and applications in organic synthesis. ${ }^{1}$ In this context, Pd-derivatives have been widely developed, ${ }^{2}$ since they are readily available and easily prepared, and because it is easy to modulate their electronic and steric properties. They are also outstanding for their rich chemistry, due to the facile redox interchange between the two stable $\mathrm{Pd}(\mathrm{II}) / \mathrm{Pd}(0)$ oxidation states, and as a result of their compatibility with a great diversity of functional groups. ${ }^{3}$ The cyclopalladated $^{4}$ complexes (Figure 1), a special class of organopalladium derivatives, are cyclic species containing one Pd-C bond (alkyl or aryl) intramolecularly stabilized by at least one neutral donor atom (D).

\section{Figure 1.}

Figure 1. General structures of cyclopalladated complexes (or palladacycles)

Palladacycles have shown a widespread use in organic synthesis, mainly due to the high reactivity of the $\mathrm{Pd}-\mathrm{C}$ bond. The $\mathrm{Pd}$ atom is usually incorporated to the organic skeleton with a high selectivity, therefore the subsequent functionalization have to occur with the same selectivity. The huge amount of work developed in this area has been reviewed several times ${ }^{5}$ from different points of view. This revision is organized based on the type of bond created: C-hal, C-O, C-N, C-P, C-S and, of course, C-C. The introductory section aims to provide a general survey of the possibilities arising from the use of orthopalladated complexes, like what type of reagents and processes allow the formation of a given $\mathrm{C}-\mathrm{X}$ bond. We also intend to present very succinctly some representative work published up to 2005. The most relevant contributions to the formation of each type of bond from 2005 up to now will be discussed in subsequent sections, with special emphasis in recent oxidative couplings and in the resurgence of the palladium chemistry in high oxidation states.

The insertion of carbon monoxide ( $\mathrm{CO}$ ) into the $\mathrm{Pd}-\mathrm{C}$ bond of palladacycles has been thoroughly investigated since it is a suitable method for the stoichiometric synthesis of carbo- and heterocycles through C-C coupling under mild conditions. ${ }^{4}$ In 1967, Takahashi and Tsuji were among the first authors to report this type of procedure. ${ }^{6}$ They studied the carbonylation of dinuclear palladated azobenzenes $\mathbf{1}$, and the mechanism proposed by them consisted in the initial bonding of the $\mathrm{CO}$ to the metal (2) followed by the insertion into the $\mathrm{Pd}-\mathrm{C}$ bond (3), reductive coupling and hydrolysis (4, Figure 2). 


\section{Figure 2}

Figure 2. Proposed mechanism for the insertion of $\mathrm{CO}$ into azobencene-palladacycles 1

Similar reactions have been successfully performed in a wide variety of complexes derived from benzylamine, ${ }^{7 \mathrm{a}} 1$-naphthylamine, ${ }^{7 \mathrm{~b}}$ and many other substrates. The nature of the donor atom is also very relevant, since it has been reported that $\mathrm{CO}$ insertion into $\mathrm{S}$-containing palladacycles proceeds in milder conditions than those occurring on the $\mathrm{N}$ containing congeners. ${ }^{4}$ The isonitriles, which are species isoelectronic with $\mathrm{CO}$, also react giving migratory insertions. ${ }^{4,5 f}$ The treatment of orthopalladated dimer $\mathbf{5}$ with isonitriles lead to the cleavage of halide bridges to give isonitrile-bonded products 6 (Figure 3), ${ }^{5 f}$ which evolve on heating to give dimeric iminoacyl complexes 7 . In the same way, indazolines are prepared by the reaction of azobenzene cyclopalladated $\mathbf{1}$ with isonitriles. ${ }^{8 b, c}$ In some cases, multiple insertions are possible and a triple isocyanide insertion on arylpalladium complexes has also been reported. ${ }^{4}$

\section{Figure 3}

Figure 3. Insertion of isonitriles into N,N-dimethylbenzylamine palladacycle

Other well known C-C bond forming process is the reaction of palladacycles with internal alkynes. ${ }^{9}$ The cyclopalladated complexes with $\mathrm{N}$ as donor atom are the best precursors to undergo alkyne insertion, since they are more reactive than the corresponding palladacycles containing $\mathrm{S}$ or $\mathrm{P}$ as donor atoms. ${ }^{4}$ It is difficult to control the number of inserted alkynes, since mono- and multi- (usually two or three) insertions can occur. The latter are the most frequent due to the high reactivity of the Pd-C bond, although the reaction conditions, the type of alkyne and the ancillary ligands have a clear influence over the outcome of the reaction. ${ }^{9}$ The reaction of cyclopalladated N,Ndimethylferrocenylamine $\mathbf{8}$ with internal alkynes gives the product of double insertion (9, Figure 2, left), ${ }^{9 \mathrm{a}, \mathrm{b}}$ while cyclopalladated complex of benzylpyridine $\mathbf{1 0}$ gives a monoinsertion product. $^{9 c, d}$ The insertion of asymmetric alkynes usually occurs regioselectively, in such a way that the smallest group is located on the side of the palladated carbon atom. If the steric hindrance is similar at both sides of the alkyne, then the electronic requisites are relevant to govern the regioselectivity. For instance, the insertion of $\mathrm{PhC} \equiv \mathrm{CCO}_{2} \mathrm{Et}$ into the $\mathrm{Pd}-\mathrm{C}$ bond leaves the electron-withdrawing $\mathrm{CO}_{2}$ Et group located near to the palladated carbon atom (Figure 4, right). ${ }^{9 \mathrm{e}}$

\section{Figure 4}

Figure 4. Insertion of alkynes into different palladacycles derived from amines 
Examples of the large number of heterocycles prepared by this method, such as $\alpha$ pirones, ${ }^{9 \mathrm{f}}$ indenones, ${ }^{9 \mathrm{~g}, \mathrm{~h}}$ hetero-spyrocycles,${ }^{9 \mathrm{i}}$ cyclazines,${ }^{9 \mathrm{j}}$ are shown in Figure 5.

\section{Figure 5}

Figure 5. Different heterocycles obtained by alkyne insertion reactions

Cyclopalladated complexes react smoothly with different alkenes, affording vinyl derivatives 15,,${ }^{4,5 f, 10}$ as shown in Figure 6 for the coupling of the palladated complex 5 and a vinyl ketone. ${ }^{9 a}$ Only terminal alkenes $\mathrm{H}_{2} \mathrm{C}=\mathrm{CRR}$ ' $\left(\mathrm{R}, \mathrm{R}^{\prime}=\mathrm{H}, \mathrm{Ph}, \mathrm{MeCO}, \mathrm{EtCO}\right.$, $\mathrm{MeCO}_{2}$ ) are reactive in these processes. ${ }^{10}$ In some cases the insertion of the alkene is alternated with the insertion of $\mathrm{CO}$.

\section{Figure 6}

Figure 6. Vinylation of benzylamine palladacycle 5

The reaction of allenes with palladacycles plays a significant role in the preparation of organic products and proceeds through the insertion of the allene into the $\mathrm{Pd}-\mathrm{C}$ bond to give a $\pi$-allylpalladium intermediate. ${ }^{4,5 f}$ The palladated tetralone ketimine 16 reacts with stoichiometric amounts of 1,1-dimethylallene ${ }^{11}$ to afford a mixture of regioisomers resulting from the nucleophilic attack of the iminic nitrogen on both terminal carbons of the $\pi$-allyl group (Figure 7). The reaction is under kinetic control, and the $\mathrm{N}$ atom attacks to the allyl unit at the most substituted allylic carbon, giving the less crowded transition state. The kinetic product $\mathbf{1 7}$ can be converted to the thermodynamic isomer 18 by reflux with catalytic amounts of $\mathrm{Pd}\left(\mathrm{PPh}_{3}\right)_{4} .^{11}$

\section{Figure 7}

Figure 7. Allene Insertion into the Pd-C Bond of cyclopalladated tetralone ketimine

The reaction of the cyclometallated complexes with halogen sources produces, in most cases, the halogenation of the metallated position, providing a convenient route for the synthesis of halogenated compounds. It is known that the halogenation of arenes, bromination in particular, is one of the most selective electrophilic reactions affording, almost exclusively, para-substituted products. The use of cyclometallated complexes, for instance 19, changes the selectivity in favor of ortho-substituted compounds $\mathbf{2 0}$ (Figure 8). ${ }^{9 \mathrm{a}, 12 \mathrm{a}}$ Precedents were found in the synthesis of ortho-halogenated products from acetanilide, ${ }^{12 \mathrm{~b}}$ 2-pyridylferrocene ${ }^{12 \mathrm{c}}$ or dimethylaminoferrocene. ${ }^{12 \mathrm{~d}}$ Palladacycles can also perform regiospecific reactions with acyl halides to give 2-acyl derivatives. ${ }^{4,13}$ The reactions take place better with electron-releasing substituents on the aromatic ring.

\section{Figure 8}

Figure 8. Example of an halogenation reaction on a cyclopalladated complex 
In addition to the use of palladacycles as synthetic intermediates, it is necessary to mention here that these complexes have been widely used as precatalysts in many types of catalytic reactions. ${ }^{5 a}$ Earlier examples involved hydrogenations ${ }^{14 a}$ or reductions of nitro-compounds. ${ }^{14 b, c}$ The seminal report of Herrmann et al. in 1995 about the synthesis and applications of the cyclopalladated $\mathrm{P}(o-\mathrm{tol})_{3} 21$ in catalytic C-C couplings was the starting point of a renewed interest. ${ }^{15 a}$ Since then hundreds of cyclopalladated complexes (Figure 9) have been used as precatalysts in a great variety of cross coupling reactions (Heck, Suzuki, Stille, Sonogashira, Negishi, etc). ${ }^{3,5 i, 15}$ However, in many cases, the palladacycles are just a reservoir of some sort of $\mathrm{Pd}(0)$ (nanoparticles, for instance), which are the true catalytic species. This kind of reactions are still one of the main focus of research and significant advances are expected on this topic. This part it is out of the scope of this review, and no further mention will be made in this revision.

\section{Figure 9}

Figure 9. Cyclopalladated complexes as catalysts in cross coupling reactions

The range of available reactions involving palladacycles has been increased in the last five-six years due to the introduction of oxidative couplings. Therefore, in addition to the reactivity already presented, new processes for the formation of $\mathrm{C}-\mathrm{O}, \mathrm{C}-\mathrm{N}, \mathrm{C}-\mathrm{S}$ and $\mathrm{C}-\mathrm{C}_{\text {aryl }}$ bonds have been developed. The methodology that will be presented here can be competitive, or at least alternative, with respect to classical organic procedures. Moreover, in some cases it is catalytic in palladium, improving standard methods. The achieved improvement is recognized by the fact that part of a recent volume of Chemical Reviews has been devoted to this topic. ${ }^{18}$

\section{2.- CARBON-HALOGEN BOND FORMATION}

The selective halogenation of aromatic molecules is a strategic transformation due to the multiple roles displayed by halogenated species in organic chemistry. For example, they are essential components of a considerable variety of pharmaceutical, agrochemical or bioactive natural products, ${ }^{19}$ as well as key precursors in cross-coupling reactions ${ }^{20}$ and in the synthesis of organolithium ${ }^{21}$ and Grignard reagents. ${ }^{22}$ The use of cyclopalladated compounds as intermediaries for the introduction of the halogen functionality has emerged in the last decades as a very attractive strategy because it displays a total regioselectivity for ortho-halogenated compounds, thus providing a complementary method to the most commonly used approaches such as electrophilic 
aromatic substitution or directed-lithiation. Moreover, it eliminates the need to use electron-rich substrates or strong acids/bases.

Halogenation through cyclopalladated compounds employing directly $\mathrm{X}_{2}(\mathrm{X}=\mathrm{I}, \mathrm{Br}$, $\mathrm{Cl})$ as a source of the halogen is a reliable approach for the synthesis of organic halogenated molecules, availed by a substantial number of literature reports in the last decades (see also Introduction). ${ }^{23}$ Recently this strategy has been applied successfully to the stoichometric ortho-functionalization of several aminoacids 25-28 (Figure 10a,b). ${ }^{24}$ In the case of $(R)$-phenylglycinate methyl ester 28 the reaction takes place with partial enantioselectivity, and values of $e e$ up to $87 \%$ are obtained.

\section{Figure 10}

Figure 10. Palladacycle-mediated halogenations using $X_{2}$ as source of halogen.

The group of $\mathrm{Yu}$ et al. reported that the combination of $\mathrm{Pd}(\mathrm{OAc})_{2}, \mathrm{I}_{2}$ and oxazolines as directing groups in $\mathbf{2 9}$ is an effective strategy for the iodination of unactivated alkyl groups (Figure 10c), offering a valuable route for the functionalization of $\mathrm{C}\left(\mathrm{sp}^{3}\right)-\mathrm{H}$ bonds (31) under mild conditions. ${ }^{25}$ The intermediate palladacyclic species $\mathbf{3 0}$ was fully characterized, and resulted to be a trinuclear Pd complex. Furthermore, the addition of 1 equiv. of $\mathrm{AgOAc}$ or $\mathrm{PhI}(\mathrm{OAc})_{2}$, which in the presence of $\mathrm{I}_{2}$ generate IOAc "in situ", allows to close a catalytic cycle, and, consequently, to work with catalytic amounts of the Pd source. Remarkably, the protocol displays a high selectivity for activation of primary over secondary $\mathrm{C}-\mathrm{H}$ bonds, and asymmetric iodinations are accessible when the directing oxazoline ring has a stereogenic center. This protocol was later adapted for carboxylic acid-directed iodination and bromination of $\mathrm{C}\left(\mathrm{sp}^{2}\right)-\mathrm{H}$ bonds $(32$, Figure 10d), although the presence of inorganic bases, organic bases or tetralkylammoniun salts was needed to achieve high conversions of $\mathbf{3 3}{ }^{26}$

Currently, considerable amount of work is devoted to find more convenient sources of the halogen atoms for these Pd-mediated reactions. Several halogenating reagents have emerged as practical alternatives, $\mathrm{N}$-halosuccinimides being the most frequently employed among them. The ability of this family of molecules to halogenate compounds, primarily by electrophilic aromatic substitution reactions, is wellestablished in organic synthesis. ${ }^{27}$ Interestingly, mediation through cyclopalladation could alter totally the regiochemistry observed, increasing notably the range of halogenated substrates accessible from the same precursor. The reaction between the aromatic oxime 34 showed in the Figure 11a and NBS (N-bromosuccinimide) furnishes meta-brominated products $\mathbf{3 5}$, but only the ortho derivative $\mathbf{3 6}$ is observed when $\mathrm{Pd}$ is 
present. ${ }^{28}$ Also the aromatic ring undergoing substitution can be modified by the intermediacy of palladacycles, a concept nicely illustrated in the Figure $11 \mathrm{~b}$ where the heterocycle or the arene ring $\mathbf{3 7}$ are selectively halogenated $(\mathbf{3 8}, \mathbf{3 9})$ depending on the absence or presence of $\mathrm{Pd} .{ }^{28}$ Until today, a considerable variety of directing groups have been exploited for the selective introduction of halogens on aromatic molecules by combination of Pd sources and N-halosuccinimides, i.e. oximes, pyrazols, pyridines, isoquinolines, amides, etc. ${ }^{28,29}$ In spite of the success achieved with these halogenating reagents sometimes they act as an excessively reactive source of the halogen, causing the formation of undesired products, for example poly-halogenated compounds. In some of these cases the use of "milder" halogenating regents have permitted to overcome the problem. The use of $\mathrm{CuCl}_{2}$ or $\mathrm{CuBr}_{2}$ has been proved as a very interesting option, which for instance permits to carry out the ortho-chlorination of amides $\mathbf{4 0}$ in a selective way (41), while the employment of NCS afforded the para-substitued derivative $\mathbf{4 2}$ as major product (Figure 11c) ${ }^{30}$ Interestingly, totally selective protocols for the mono orthohalogenation of arylpiridines $\mathbf{4 3}$ have been developed very recently (44, Figure 11d,e). The first one is based on the use of catalytic $\mathrm{CuCl}_{2}$ and $\mathrm{PdCl}_{2}(\mathrm{NCMe})_{2}$ in combination with stoichiometric $\mathrm{ArSO}_{2} \mathrm{Cl}$, species which were postulated as the ultimate sources of "Cl". In the second one, an innovative halogenation approach based on the combination of $\mathrm{Pd}$ and electrochemical oxidation permits to functionalize arylpyridines 45 to give excellent yields of 46, and eliminates the need to remove the remaining oxidant or its byproducts. ${ }^{32}$ In this method $\mathrm{HX}(\mathrm{X}=\mathrm{Cl}, \mathrm{Br})$ play a dual role, working as both supporting electrolyte and source of the halogen.

\section{Figure 11}

Figure 11. Halogenating agents used in $C-X$ forming reactions via palladacycles.

Hypervalent iodine reagents, principally $\mathrm{PhICl}_{2}$, also have been proved as competent halogenating agents. However, modest yields and low selectivity are typically observed with these reagents, due to the presence of competing side reactions. $^{28,29,33}$ Although limited applications in synthesis are displayed by these reagents, their powerful oxidant character has been exploited for the generation of isolable halogenated Pd complexes in high oxidation state (Figure 12), namely dimeric $\mathrm{Pd}(\mathrm{III}) 47$ or monomeric $\mathrm{Pd}(\mathrm{IV})$ complexes 48, 49 generated by two-electron oxidation process.

\section{Figure 12}

Figure 12. Selected high oxidation state $\mathrm{Pd}$ complexes synthesized using $\mathrm{PhICl}_{2}$. 
These species have been studied in detail as models, and have provided notable mechanistic insights into the halogenation reactions promoted by palladacycles. ${ }^{34}$ As discussed for the C-O bond formation section (see below), several studies offer clear evidences for the feasibility of $\mathrm{Pd}(\mathrm{IV}) / \mathrm{Pd}(\mathrm{II})$ cycles involving monomeric $\mathrm{Pd}(\mathrm{IV})$ species $(\mathbf{4 8}, \mathbf{4 9})$ as key intermediates in halogenation processes. ${ }^{34 a, c}$ However, Ritter et al. just reported outstanding results that suggest that dimeric $\mathrm{Pd}(\mathrm{III})$ intermediates $\mathbf{4 7}$ are also possible, particularly when bridging carboxylate ligands are available. ${ }^{34 \mathrm{~b}}$

In contrast to the impressive success enjoyed with chlorination, bromination and iodination mediated via cyclopalladation, the analogous fluorination processes remains as a challenging task. This is mainly due to the problems derived from work with the conventional sources of fluorine atoms. Prompted by the development of practical fluorinating reagents, promising advances have been made in the last years. N-Fluoro2,4,6-trimethylpyridinium triflate 50, in the presence of $\operatorname{Pd}(\mathrm{OTf})_{2}$, is an excellent fluorinating ligand for N-protected benzylamines 51 (Figure 13a), ${ }^{35}$ species with a considerable value in organic synthesis because it gives access to a broad range of fluoride-containing functionalized aromatic substrates 52. Sanford et al. have carried out an exhaustive study of $\mathrm{Pd}$ catalyzed benzylic fluorination of 8-methylquinoline $\mathbf{5 3}$

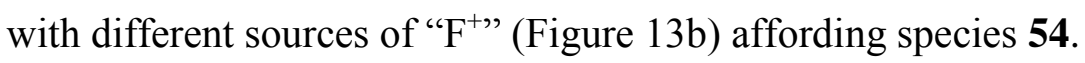

\section{Figure 13}

Figure 13. Pd catalyzed fluorination via cyclopalladation.

Selectfluor, 4-iodotoluenedifluoride, $\mathrm{N}$-fluorodisulfonamide, $\mathrm{N}$-fluoropyridinium and $\mathrm{N}$-fluoro-2,4,6-trimethylpyridinium salts have been tested, among others, the last one displaying notably the best results for this reaction. ${ }^{36}$ Conversely, $N$ fluoropyridinium salt was found as the optimal agent for the ortho-fluorination of arylpyridines 55 (Figure 13c). ${ }^{36 a}$ Once more, stoichometric oxidation carried out very recently with model complexes have indicated that $\mathrm{Pd}(\mathrm{II}) / \mathrm{Pd}(\mathrm{IV})$ cycles are plausible mechanisms for these fluorination processes, ${ }^{36 \mathrm{~b}, \mathrm{c}}$ however the nature of the catalytic intermediates has not been fully elucidated yet.

\section{3.- CARBON-OXYGEN BOND FORMATION}

The direct oxygenation of $\mathrm{C}-\mathrm{H}$ bonds represents a powerful approach for the synthesis of alcohols, ethers, and related products, species which display widespread applications in the chemical industry and are invaluable precursors in organic synthesis. ${ }^{37}$ In particular, the selective oxygenation of $\mathrm{C}-\mathrm{H}$ bonds of organic molecules via combination of cyclopalladation and oxidation has emerged as a very attractive 
strategy. Over the last decade, this method has been proven particularly fruitful for the production of acetoxy and alkoxy functionalizated derivatives, either in catalytic and stoichiometric versions. These transformations have been applied to numerous organic scaffolds with different structures and occur with excellent regio- and chemoselectivities. While $\mathrm{Pd}(\mathrm{OAc})_{2}$ has been the preferred choice for the metallic source, a considerable variety of oxidants have been employed to promote the formation of the ortho-oxygenated products. Among them, hypervalent iodine (III) reagents have undoubtedly received the most attention, due to their low toxicity, easy handling, and high reactivity. The most well-known representative of this family is the (diacetoxyiodo)benzene, $\mathrm{PhI}(\mathrm{OAc})_{2}$. However, the choice of the best oxidant has to be optimized in each case since there exist no universal oxidant.

Sandford and coworkers have developed a pioneering and simple protocol for the oxygenation of benzo[ $h]$ quinoline derivatives $\mathbf{5 7}$ under mild conditions (Figure 14a). ${ }^{38}$ The strategy is based on the combination of catalytic $\mathrm{Pd}(\mathrm{OAc})_{2}$ and stoichiometric amounts of $\mathrm{PhI}(\mathrm{OAc})_{2}$, the pyridine acting as the directing group. The products $\mathbf{5 8}$ are acetoxylated at the less sterically hindered position, and are isolated in high yield when the reactions are carried out in $\mathrm{AcOH}$. Remarkably, arylalkylether derivatives $\mathbf{5 9}$ are also accessible in excellent yields by a simple change of the solvent from $\mathrm{AcOH}$ to an alcohol ROH (Figure 14a). ${ }^{38}$ The "in situ" formation of $\mathrm{PhI}(\mathrm{OR})_{2}$ by reaction between the corresponding alcohol and $\mathrm{PhI}(\mathrm{OAc})_{2}$ is believed to be a key step in these syntheses. The acetoxylation protocol was further expanded to a considerable number of derivatives $(43,60-63)$, pyridine moieties serving as excellent directing groups (Figure $14 \mathrm{~b}, \mathrm{c}$ ) as well as others nitrogen-based directing groups, like oximes $\mathbf{3 4}$, heterocycles or azobenzene (Figure 14d). ${ }^{39}$ Pyrrolidinones $^{39}(\mathbf{6 4}, \mathbf{6 5})$ and $N$-benzylpicolinamides ${ }^{40}$ have been acetoxylated employing similar protocols (Figure 14e), as well as aminoacids (27, 66), which have been ortho-functionalized with -OAc or -OR groups (Figure $14 \mathrm{f}){ }^{24 \mathrm{c}}$ Interestingly enough, the use of $\mathrm{PhI}(\mathrm{OAc})_{2}$ as terminal oxidant also proved efficient for the acetoxylation of both benzylic $(\mathbf{5 3}, \mathbf{6 7})$ and unactivated $\mathrm{sp}^{3} \mathrm{C}-\mathrm{H}$ bonds $(68,69)$ (Figure $14 \mathrm{~g}, \mathrm{~h})$, using pyridines ${ }^{38}$ and oximes ${ }^{41}$ as directing groups.

\section{Figure 14}

Figure 14. $\mathrm{C}-\mathrm{O}$ bond forming reactions mediated by palladacycles with $\mathrm{PhI}(\mathrm{OAc})_{2}$

Regardless of the success displayed with $\mathrm{PhI}(\mathrm{OAc})_{2}$, the fact that one equivalent of toxic iodobenzene is generated, in concert with the high-cost of this stoichometric oxidant, sparked the search for other more environmentally benign and cost-effective 
oxidants. A polymer immobilized version of this reagent $\mathbf{7 0}$ has been tested in many acetoxilation processes by the Sanford group, ${ }^{42}$ displaying comparable yields and offering the advantage that it can be easily recovered and recycled (Figure 15a). Another interesting option is the use of IOAc as terminal oxidant, which was proven by the Yu's group to be able to promote the Pd-catalyzed acetoxylation of Boc-protected $N$-methylamines 71 (Figure 15b). ${ }^{43}$ The IOAc was generated "in situ" by reaction between $\mathrm{AgOAc}$ and $\mathrm{I}_{2}$, and no reaction was observed when $\mathrm{AgOAc}$ or $\mathrm{I}_{2}$ were used separately. Several functional groups are tolerated in this protocol, like amides, ketones, esters and sulfonates. There is one significant drawback in absence of para substituents, because in some of these cases electrophilic iodination can took place simultaneously, generating the respective $p$-iodinated acetoxylation products.

One of the best alternatives to the use of I(III) reagents are the environmentally benign and inexpensive peroxides. Sandford and coworkers carried out in 2006 an exhaustive investigation of $\mathrm{Pd}(\mathrm{OAc})_{2}$-catalyzed acetoxylation of the oxime ether showed in Figure 15c, testing a great variety of peroxide oxidants in $\mathrm{AcOH} / \mathrm{Ac}_{2} \mathrm{O} .{ }^{39 \mathrm{~b}}$ All peroxides screened afforded positive results, performing noticeably better oxone ${ }^{\circledR}$ (oxone $^{\circledR}=2 \mathrm{KHSO}_{5} \cdot \mathrm{KHSO}_{4} \cdot \mathrm{K}_{2} \mathrm{SO}_{4}$ ) and $\mathrm{K}_{2} \mathrm{~S}_{2} \mathrm{O}_{8}$. The scope of this transformation was examined with both oxidants to a diverse array of organic derivatives, displaying an excellent versatility. For instance, compounds with oximes 34, ketones, aldehydes, amides $(\mathbf{4 0}, \mathbf{7 4})$ and isoxazolines (29) as directing groups were found to undergo this transformation. In addition, this methodology was found to be compatible with a wide variety of functional groups as halides, nitriles, ethers, trifluoromethyl, methyl, etc.

\section{Figure 15}

Figure 15. C-O bond forming reactions mediated by palladacycles and other oxidants

Wang et al. reported a related protocol for the ortho-acetoxylation of anilides $\mathbf{4 0}$ (Figure 15d). ${ }^{44}$ They found that the best oxidant is potassium persulfate, affording the expected product $\mathbf{7 3}$ in $77 \%$ yield. No reaction took place with $\mathrm{O}_{2}$ as oxidant, only traces were produced with $\mathrm{PhI}(\mathrm{OAc})_{2}$, oxone ${ }^{\circledR}$ or $m$-chloroperoxibenzoic acid, and modest yields were observed with tert-butyl hydroperoxide (TBHP). The generality of the reaction was investigated under the optimized conditions. The protocol exhibited an excellent tolerance to either electron-donating or electron-withdrawing substituents.

Recent work has showed that combination of oxone ${ }^{\circledR}$ and $\mathrm{Mn}(\mathrm{OAc})_{2}$ is capable to promote the acetoxylation of unactivated $\mathrm{Csp}^{3}-\mathrm{H}$ bonds in amidoquinolines 74 (Figure 15e). ${ }^{45}$ An intermediate of this reaction was isolated and fully characterized, including 
X-ray diffraction. The structure shows a palladacycle with both the amide and the quinoline bonded to the metallic center. This kind of bonding seems to facilitate the activation of the typically inert $\mathrm{Csp}^{3}-\mathrm{H}$ bonds, affording 75 . The reaction was further applied to aminoacid derivatives with high levels of diasteroselectivity and conversion. Another interesting example of oxygenation of $\mathrm{Csp}^{3}-\mathrm{H}$ bonds has been recently described (Figure 15f). ${ }^{46}$ In this approach $\mathrm{MeCO}_{2} \mathrm{O}-t$-Bu and lauroyl peroxide were found to be competent oxidants for the Pd-catalyzed acetoxylation of oxazolines 29. The reaction is compatible with several additional functionalities like imides, esters, ketals and alkyl chlorides. Very exciting recent results demonstrated that the totally inexpensive and ready available dioxygen can function as efficient oxidant in acetoxylation reactions (Figure $15 \mathrm{~g}$ ). The reaction carried out over 8-methylquinoline 53 and related substrates proceeds with $\operatorname{Pd}(\mathrm{acac})_{2}$ as the catalyst in conjunction of pyridine-2,6-carboxylate $\left(\mathrm{H}_{2} \mathrm{hpda}\right)$ in $\mathrm{AcOH} / \mathrm{Ac}_{2} \mathrm{O}$ under $\mathrm{O}_{2} .{ }^{47}$ The Pd-catalyzed orthohydroxylation of benzoic acid 32 (Figure 15h, BQ = benzoquinone) occurs under $1 \mathrm{~atm}$. of $\mathrm{O}_{2}{ }^{48}$ From both an environmental and economic point of view the finding that molecular oxygen is a competent oxidant represent an exceptional advance.

The generally accepted mechanism for these $\mathrm{C}-\mathrm{O}$ bond forming reactions involves an initial generation of the cyclopalladated compound, usually through $\mathrm{C}-\mathrm{H}$ bond activation. The palladacycle undergoes a two-electron oxidation, with subsequent formation of the $\mathrm{C}-\mathrm{O}$ bond by reductive elimination. However, it has proven challenging to directly investigate the proposed oxidation and reductive elimination steps. In particular, the mechanism of $\mathrm{C}-\mathrm{H}$ oxygenation with $\mathrm{PhI}(\mathrm{OAc})_{2}$ has been explored in considerable detail. Initial studies $^{49}$ indicated the participation of monomeric $\mathrm{Pd}(\mathrm{IV})$ as intermediates in these processes, meaning that $\mathrm{Pd}(\mathrm{IV}) / \mathrm{Pd}(\mathrm{II})$ cycles are involved in the mechanistic description. However, recent work has disclosed evidences for the intermediacy of bimetallic $\mathrm{Pd}(\mathrm{III})$ species with carboxylate bridges in the acetoxylation of phenyl pyridines. ${ }^{50}$ These contributions had set up a debate over the question if analogous $\mathrm{Pd}(\mathrm{III})$ species are also responsible for a large class of $\mathrm{C}-\mathrm{H}$ oxidations previously proposed to proceeded via $\mathrm{Pd}(\mathrm{IV})$ intermediates, especially when there are available $\mathrm{OAc}$ ligands. Besides $\mathrm{PhI}(\mathrm{OAc})_{2}$, considering the large variety of substrates and oxidants employed, the elucidation of the mechanism operating in each case is an intricate task, which is yet to be solved, and constitutes one of the challenges for the future. 


\section{4.- CARBON-NITROGEN BOND FORMATION}

The transition metal-mediated carbon-nitrogen bond formation is an active research subject, ${ }^{51}$ since compounds containing $\mathrm{C}-\mathrm{N}$ bonds are of immense importance in many areas of chemistry. For instance they are found in abundance in pharmaceutical agents or materials, natural bioactive products and so on. The methodology based on the combination of both cyclopalladation and oxidation in the presence of an appropriate $\mathrm{N}$ source offers an attractive route for the direct conversion of $\mathrm{C}-\mathrm{H}$ bonds into $\mathrm{C}-\mathrm{N}$ bonds with remarkable regio-, stereo- and chemioselectivities, in an analogous way as described above for the creation of $\mathrm{C}-\mathrm{X}$ and $\mathrm{C}-\mathrm{O}$ bonds, alternative to classical methods. ${ }^{52}$ Several reports exploiting this strategy have appeared in the literature recently, enabling the selective functionalization of substrates where the $\mathrm{C}-\mathrm{N}$ bond is formed either by intermolecular or by intramolecular $\mathrm{C}-\mathrm{N}$ coupling.

A pioneering work in this area, and until today the only example of intermolecular catalytic formation of $\mathrm{C}-\mathrm{N}$ bonds via palladacycles, was reported by $\mathrm{Che}, \mathrm{Yu}$ and coworkers in 2006. ${ }^{53}$ The approach developed implies intermolecular amidation reactions, and is based on the use of catalytic amounts of $\operatorname{Pd}(\mathrm{OAc})_{2}$, together with excess of $\mathrm{K}_{2} \mathrm{~S}_{2} \mathrm{O}_{8}$ as oxidant in the presence of the relevant amide. This method was applied successfully to diverse substrates as arylpyridines 55 (Figure 16a) or aromatic and aliphatic oximes $(\mathbf{3 4}, \mathbf{8 0}$ ) (Figure 16 b,c), and it is compatible with several amides, including carbamates, acetamides and sulfonamides. The considerable versatility of this strategy is not only indicated by the diversity of the precursors employed, but also by the fact that the protocol tolerates a variety of functional groups in $\mathbf{7 8 - 8 1}$, as electroreleasing or electrowithdrawing groups, halogens, bulky substituents, etc.

\section{Figure 16}

Figure 16. $\mathrm{Pd}(\mathrm{II})$-catalyzed amidation of arylpyridines and oximes.

Recently Sandford et al. reported a stoichiometric conversion of C-H bonds into amine groups via palladacyclic intermediates under mild conditions. ${ }^{54}$ The method is based on the formation of diverse palladacyclic complexes by directed $\mathrm{C}-\mathrm{H}$ activation and subsequent stoichiometric amination with $\mathrm{PhI}=\mathrm{NTs}$ or related oxidants $(\mathrm{Ts}=$ tosylate). The first investigated substrate was the chloride-bridged azobenzene dimer $\mathbf{1}$ showed in the Figure 17a, species which undergoes an unexpected double insertion of the "NTs" moiety in $\mathbf{8 2}$, as a result, probably, from a second ortho C-H activation event. The next tested palladacycles $\mathbf{8 4}$ belong to the family of the benzo[ $h]$ quinoline derivatives 57, which do not offer the possibility for a second $\mathrm{C}-\mathrm{H}$ activation (Figure 17 
b). The reaction between $\mathrm{PhI}=\mathrm{NTs}$ and the dimeric species with $\mathrm{Cl}$ or OAc bridges afforded the "NTs" insertion products 85 in low yields, and accompanied by the respective chlorinated and/or acetoxylated (59) products. In contrast, the reaction of the monomeric chloride 86 with $\mathrm{PhI}=\mathrm{NT}$ s furnished cleanly the desired product. The reactivity of $\mathbf{8 6}$ with other oxidants based on hypervalent iodide, derived from electronically diverse benzenesulfonamides, proceeded in modest to good yields. Once the optimal conditions for the insertion reactions were found, a series of protonolysis reactions were tested with the goal to liberate the newly aminated product. The addition of an excess of $\mathrm{HCl}$ displayed the best results, allowing the quantitative cleavage of the $\mathrm{Pd}-\mathrm{N}$ bond (Figure 17b) and subsequent release of the organic species $\mathbf{8 8}$. This kind of reactivity was expanded to palladacycles of the benzo $[h]$ quinoline family containing $\mathrm{Pd}-$ $\mathrm{Csp}^{3}$ bonds, reflecting the high versatility and efficacy of the method.

\section{Figure 17}

Figure 17. Amination of palladacycles with hypervalent iodide oxidants.

A revolutionary work in the $\mathrm{C}-\mathrm{N}$ intramolecular bond coupling area was reported by Buchwald and coworkers in 2005. ${ }^{55}$ The synthesis of functionalizated carbazoles 89 was achieved in one synthetic step by the cyclization of 2-phenylacetanilides 90 (Figure 18a). The key feature of this method is the combination of catalytic amounts of $\mathrm{Pd}(\mathrm{OAc})_{2}$ and $\mathrm{Cu}(\mathrm{OAc})_{2}$ in the presence of oxygen. The method tolerates a variety of electrowithdrawing and electrodonating groups on both aromatic rings. A related process (Figure 18b) was described recently by Gaunt et al., ${ }^{56}$ which found that derivatives of 2-phenylanilines 91 undergo, in the presence of $\mathrm{Pd}(\mathrm{OAc})_{2}$ as catalyst and $\mathrm{PhI}(\mathrm{OAc})_{2}$ as oxidant, intramolecular cyclizations to afford substituted carbazoles $\mathbf{8 9}$ as a result of $\mathrm{C}-\mathrm{N}$ coupling. The reaction was amenable to a range of groups on both rings or even on the $\mathrm{N}$-substituent, which also could be removed if necessary.

\section{Figure 18}

Figure 18. N-heterocycles synthesized by intramolecular C-N coupling.

During the last years of the past decade J.-Q. Yu and coworkers described an impressive method for the synthesis of indolines 92, which is based on intramolecular amination reactions carried out over arylethylamines 51 (Figure 18c). In a first approach, ${ }^{57}$ they used a tandem $\mathrm{C}-\mathrm{H}$ bond-iodination/C-N bond forming reaction by combination of $\mathrm{Pd}(\mathrm{II})$ and $\mathrm{Cu}(\mathrm{II})$ catalysts. Although the strategy proved to be valid for the synthesis of indolines 92, undesired acetoxylated or halogenated products were generated as by-products. In an improved version, ${ }^{58}$ several one- or two-electron 
oxidants were used, additionally to the catalytic $\mathrm{Pd}(\mathrm{OAc})_{2}$, to promote the cyclizations. Between the single electron oxidants, anhydrous $\mathrm{Ce}\left(\mathrm{SO}_{4}\right)_{2}$ performed the best results, allowing for the selective amination in good yields in most of the substrates tested. However, poor yields were found when the starting materials had electron withdrawing groups such as halides and esters. This drawback was resolved by the employ of two electron oxidants, specifically $\mathrm{F}^{+}$, generated "in situ" using the pyridinium salt $[2,4,6$ $\left.\mathrm{Me}_{3} \mathrm{C}_{6} \mathrm{H}_{2} \mathrm{NF}\right] \mathrm{BF}_{4}$. This oxidant displayed excellent results, permitting that several of the strongest electron withdrawing groups (halo, acetyl, cyano, nitro, etc) were tolerated. In both cases the presence of DMF is crucial, possibly as a labile ligand. Indolines $\mathbf{9 2}$ can be also synthesized by an alternative method based on cyclopalladation, as shown recently by the Glorius's group. ${ }^{59}$ In this work (Figure 18d), a large number of heterocycles were produced through Pd-catalyzed oxidative cyclizations of acetamides 40. These processes involve the activation of inert $\mathrm{Csp}^{3}-\mathrm{H}$ bonds. The best results were achieved when $\mathrm{AgOAc}$ and $\mathrm{Na}_{2} \mathrm{CO}_{3}$ were employed as the oxidant and base, respectively. Although a delicate balance between electronic and steric properties of the nitrogen substituent is required for the initiation of this reaction -neither carbamates, sulfonamides, primary or secondary amines worked- a broad range of substituents on the aromatic ring are tolerated, proceeding well the reactions for both electrodonating and electron withdrawing groups. Another noteworthy contribution to the field recently made by the group of J.-Q. Yu deals with the lactamization of $\mathrm{N}$-alkoxyamides $\mathbf{9 3}$ via $\mathrm{C}-\mathrm{H}$ intramolecular amination process (Figure 18e). ${ }^{60}$ Using the appropriate precursor, the method allows the synthesis of $\beta$-, $\gamma$-, and $\delta$-lactams 94 with an impressive range of accessible substituents. The employ of $\mathrm{Pd}(\mathrm{OAc})_{2}$ as catalysts, in concert with excess of $\mathrm{CuCl}_{2}$ and $\mathrm{AgOAc}$ are the optimal conditions for this lactamization protocol.

A novel and straightforward method to construct benzoimidazoles 97 was developed by Yang, Shi et al, ${ }^{61}$ which is based on the transformation of N-phenylbenzimides 95 into the aforementioned heterocycles 97 by means of palladacycles 96 followed by intramolecular C-N bond formations (Figure 18f). Initially, stoichiometric syntheses were carried out employing $\mathrm{PdCl}_{2}$ to promote the cyclopalladation. The palladacycles 96 were fully characterized, including X-ray crystallography, and were found to undergo reductive elimination to form the desired products in the presence of $\mathrm{NaOAc}$ without the need for any oxidants. A catalytic version of this transformation was developed. The best conditions found were catalytic amounts of $\left[\mathrm{PdCl}_{2}(\mathrm{NCPh})_{2}\right]$ in combination with stoichiometric $\mathrm{Cu}(\mathrm{OAc})_{2}$ under $\mathrm{O}_{2}$ atmosphere. Interestingly, the 
presence of tetramethylthiourea (TMTU) as additive improved dramatically the yields, probably due to its potential ability to stabilize Pd(II) species. ${ }^{61}$ The substitutions on the aromatic moieties were crucial for the success of the reaction, since only electrondonating groups were compatible.

An innovative tandem amination approach, which allows for the transformation of easily accessible $o$-haloaryl acetylenic ketones 98 and primary amines into valuable 4quinolones 99, was developed by $\mathrm{Xu}$ and collaborators in recent times. ${ }^{62}$ In this original strategy, a sequential double $\mathrm{C}-\mathrm{N}$ bond formation is exploited for the construction of the mentioned nitrogen-containing heterocycles (Figure $18 \mathrm{~g}$ ). The system $\mathrm{Pd}_{2}(\mathrm{dba})_{3} / \mathrm{PPh}_{3}$ turned out to be the best choice for the metal source, additionally $\mathrm{K}_{2} \mathrm{CO}_{3}$ as base and dioxane as solvent displayed the best behaviour. Under these optimized conditions a wide range of multisubstituted 4-quinolones 99 were prepared, showing the versatility of the approach. A mechanistic analysis of these transformations put forward the intermediacy of palladacycles as a key step in the process. Muñiz has designed another remarkable double amination process, ${ }^{63}$ in which 2,2 '-diamidostilbenes $\mathbf{1 0 0}$ are transformed into bisindolines 101 and related heterocycles (Figure 18h) with total diastereoselectivity. The strategy makes use of the $\mathrm{Pd}(\mathrm{OAc})_{2}$ as catalyst and $\mathrm{PhI}(\mathrm{OAc})_{2}$ as oxidant, with the combination of $\mathrm{NMe}_{4} \mathrm{Cl}$ and $\mathrm{NaOAc}$ as the most convenient base.

At this point the mechanistic scenario for these $\mathrm{C}-\mathrm{N}$ bond forming processes is complicated, fundamentally because the nature of the reactive intermediates remains unclear, thus leading to several conceivable mechanisms. Very recently, Cundari and coworkers carried out a complete investigation of the mechanism of the reaction between $\mathrm{PhINTs}$ and $[\mathrm{PdCl}($ benzo[ $h]$ quinoline)py] 86 (Figure 17b) using DFT methods. ${ }^{64}$ In this elegant work the authors concluded that the most plausible option is a concerted or a dissociative imido transfer mechanism, the most plausible intermediate being, therefore, a Pd(IV) imido complex. Previously to this work, in the vast majority of the cases the authors have postulated the involvement of Pd species in high oxidation, $\mathrm{Pd}(\mathrm{II}) / \mathrm{Pd}(\mathrm{IV})$ cycles being the preferred mechanistic choice. However, we consider that the possible intermediacy of dimeric $\mathrm{Pd}(\mathrm{III})$ complexes should not be ignored, especially when bridge acetate ligands are accessible.

\section{5.- CARBON-SULFUR AND CARBON-PHOSPHORUS BOND FORMATION}

Few examples of C-S bond formation processes mediated by palladacycles have been reported in spite of a promising beginning using stoichiometric amounts of $\mathrm{Pd}^{65} \mathrm{In}$ most cases these transformations involve intramolecular reactions. The first example of 
an intramolecular catalytic process was developed by Inamoto and Doi (Figure 19a). ${ }^{6 a}$ In this original work benzo[b]thiophenes $\mathbf{1 0 3}$ were synthesized via cyclization of thienols 102 promoted by a simple palladium complex such as $\left[\mathrm{PdCl}_{2}(\mathrm{COD})\right]$ or $\mathrm{PdCl}_{2}$. Although detailed mechanistic studies have not been carried out, the authors suggested an initial oxidation of the substrate to form a disulfide intermediate, the DMSO playing a dual role as solvent and as oxidant, followed by an oxidative addition reaction and the subsequent reductive elimination from the $\mathrm{Pd}(\mathrm{II})$ complex. Related catalytic reactions were reported by Batey and co-workers. N-arylthioureas 104 were converted into 2aminobenzothiazoles 105 (Figure $19 \mathrm{~b})^{66 \mathrm{~b}}$ using $\left[\mathrm{Pd}\left(\mathrm{PPh}_{3}\right)_{4}\right]$ as catalyst. It is proposed that the combination of the $\mathrm{Pd}$ complex with the oxidant $\mathrm{MnO}_{2}$ under an oxygen atmosphere allows the C-S intramolecular coupling. Recently, an interesting approach for the synthesis of polycyclic heteroarenes $\mathbf{1 0 7}$ was reported. In this strategy $\left[\mathrm{Pd}(\mathrm{OAc})_{2}\right] / \mathrm{PPh}_{3}$ catalyzes the formation of intramolecular $\mathrm{C}-\mathrm{S}$ bonds into thioetherfunctionalized indoles. (Figure 19c). ${ }^{67}$

\section{Figure 19}

Figure 19. Catalytic intra- and intermolecular C-S bond formation.

As far as we know, the only example of intermolecular C-S bond formation was recently reported by Dong et al. ${ }^{68}$ The approach developed allows for the functionalization of 2-phenylpyridines 55 (Figure 19d), catalyzed by $\left[\mathrm{PdCl}_{2}(\mathrm{NCMe})_{2}\right]$, employing arylsulfonyl chlorides as the sulphur source. This reaction affords derivatives 108 and displays tolerance to the presence of different substituents into the arylsulfonyl chlorides, with the exception of aliphatic sulfonyl chlorides, which decompose during the reaction. The only example of C-P bond coupling has been reported by Smoliakova et al. ${ }^{69}$ They describe the stoichiometric synthesis of ortho-(diphenylphosphino)-N,Ndimethylbenzylamine 109 (Figure 20) by reaction of the cyclopalladated dimer of N,Ndimethylbenzylamine 5 with $\mathrm{LiPPh}_{2}$ in THF or in toluene.

\section{Figure 20}

Figure 20. Stoichiometric C-P bond formation through a cyclopalladated complex.

\section{6.- CARBON-CARBON BOND FORMATION: ARYLATIONS}

Palladium-catalyzed $\mathrm{C}-\mathrm{C}_{\mathrm{Ar}}$ bond forming reactions are extensively applied in organic synthesis. The great majority of these processes (Heck, Suzuki, Stille, Sonogashira, Hiyama and Negishi, among others) involve two functionalized starting materials, usually an halide and an organometallic reagent. ${ }^{70}$ Several alternatives have been developed involving two main transformations: (i) a Pd-mediated $\mathrm{C}-\mathrm{H}$ activation 
step followed by (ii) a functionalization of the resulting $\mathrm{Pd}-\mathrm{C}$ bond employing arylating reagents. These strategies are compatible with the formation of cyclopalladated complexes ${ }^{4}$ in step (i), allowing for the regioselective formation of the $\mathrm{C}-\mathrm{C}_{\mathrm{Ar}}$ bond in step (ii) due to the assistance of the directing group. During the last years there has been an agitated activity in this field, ${ }^{18 a, 71}$ due to the critical importance and wide prospect of applications of these processes in organic syntheses. Some aspects of the $\mathrm{C}-\mathrm{C}$ bond formation will be covered here: intermolecular arylations from prefunctionalized and from non prefunctionalized substrates, intramolecular arylations, and other types of C-C bond couplings, such as carbonylations, alkenylation, cyanation, and others.

Catellani and co-workers have developed processes involving many different arylations of norbornene through catalytic sequential reactions. An example is shown in Figure 21, and implies palladacycle-directed aryl coupling steps. ${ }^{72}$. Although the palladacyclic intermediates are not strictly as we have defined them at the beginning of this review, their similitude and the interest of the resulting compounds are really worth of mention here. This methodology is based on the cooperative action of $\mathrm{Pd}$ and norbornene which permits to achieve selective aryl-aryl couplings. Reaction of bromobenzene with norbornene in the presence of $\mathrm{Pd}\left(\mathrm{PPh}_{3}\right)_{4}$ and $t$ - $\mathrm{BuOK}$ affords the polycyclic compound (110) represented in Figure 21. The proposed mechanism for this catalytic cycle involves palladacycle 112 and the $\sigma$-norbornyl Pd(IV) complex 113 as intermediates in the $\mathrm{C}-\mathrm{C}$ bond-forming reaction. ${ }^{72}$

\section{Figure 21}

Figure 21. Arylation of norbornene through C,C-palladacycles

This Pd-catalyzed norbornene-mediated coupling has also been applied to the reaction between ortho-substituted aryl halides and ketones, ${ }^{73 \mathrm{a}}$ heteroarenes, ${ }^{73 \mathrm{~b}}$ or many other functional groups. ${ }^{73 c}$ The intermolecular arylation of substrates containing directing groups has been developed and studied in great detail. Sanford et al. have reported the use of pyridine ${ }^{74}$ quinoline, pyrrolidine and oxazolodinones moieties as directing groups in the Pd-catalyzed arylation with I(III) salts (Figure 22), while other authors applied the same method for the arylation of anilide ${ }^{75 a}$ or benzodiazepines. ${ }^{75 b}$

\section{Figure 22}

Figure 22. Arylation of $\mathrm{N}$-containing substrates through oxidative coupling Concerning to the mechanism of these reactions, a similar situation to that described for the halogenation and oxygenation processes (sections 2 and 3, Figure 12) is found. Preliminary studies allowed to propose a mechanism in which initial $\mathrm{C}-\mathrm{H}$ activation 
gives a cyclopalladated complex 116. This intermediate was subsequently oxidized by the aryliodonium salt, $\left[\mathrm{Ph}_{2} \mathrm{I}\right] \mathrm{BF}_{4}$, to generate a $\mathrm{Pd}(\mathrm{IV})$ species 117. Reductive elimination of the arylated product $\mathbf{1 1 8}$ regenerates the catalytically active species $\mathbf{1 1 6}$ (Figure 23, left). ${ }^{74}$ Recent kinetic studies have suggested the possibility of a closely related two-electron mechanism involving dimeric high-oxidation state Pd intermediates 119/120. These complexes can be seen as a mixed-valent $\mathrm{Pd}^{\mathrm{IV}} / \mathrm{Pd}^{\mathrm{II}}$ or $\mathrm{Pd}^{\mathrm{III}}-\mathrm{Pd}^{\mathrm{III}}$ dimers (Figure 23, right), depending on the nature of the Pd-Pd interaction. ${ }^{18 a, 76}$ Complexes with the Pd ${ }^{\text {III }}-\mathrm{Pd}^{\mathrm{III}}$ dimeric unit, obtained by oxidation of acetate-bridged $\mathrm{Pd}^{\mathrm{II}}$ complexes with $\mathrm{PhICl}_{2}$ are known, ${ }^{34 \mathrm{~b}, 77}$ and their participation in these cycles can not be discarded.

Figure 23

Figure 23. Proposed mechanism ${ }^{74}$ (left) and intermediated species ${ }^{76}$ (right)

Yu et al. have reported the Pd-catalyzed arylation of aromatic substrates using arylacylperoxides as aryl sources. A mechanism involving decarboxylation to generate aryl radicals (Ar·) followed by reaction with cyclopalladated intermediates was proposed. Substrates containing pyridil (55), oxime, and oxazoline groups undergo arylation with excellent functional group tolerance (Figure 24$){ }^{78}$

\section{Figure 24}

Figure 24. Arylacyl peroxides as source of aryl fragments and oxidant

Aryl iodides have also been utilized as aryl sources. Daugulis and Zaitsev, and recently $\mathrm{Wu}$ et al. have described $\mathrm{Pd}(\mathrm{II})$-catalyzed arylation of acylanilides with aryl iodides. ${ }^{75 a, 79}$ Stoichiometric amounts of AgOAc were required for each equivalent of aryl iodide consumed (Figure 25). This methodology has been applied to the arylation of pyridines, ${ }^{80 \mathrm{a}}$ benzamides, ${ }^{80 \mathrm{~b}}$ benzylamines, ${ }^{80 \mathrm{c}}$ benzoic acids ${ }^{80 \mathrm{~d}}$ and benzoxazoles, ${ }^{79}$ among others. The group of Daugulis have also reported the ortho-arylation of N-propyl and $\mathrm{N}$-cyclohexil benzamides with aryl iodides to afford modified fluorenones and benzonitriles, respectively. ${ }^{80 \mathrm{e}}$ Fagnou has reported the direct arylation reaction of benzodioxole with aryl chlorides and bromides, ${ }^{80 f}$ while Cetinkaya et al reported the directed ortho-arylation of benzaldehyde derivatives with aryl chlorides and bromides. $^{80 \mathrm{~g}}$

\section{Figure 25}

Figure 25. Examples of arylation processes using aryl iodides as aryl sources

The formation of $\mathrm{C}-\mathrm{C}_{\mathrm{Ar}}$ bonds has also been achieved with boronic acids as aryl sources. $\mathrm{Pd}(\mathrm{OAc})_{2}$ was used as catalyst, $\mathrm{Cu}(\mathrm{OTf})_{2}$ as oxidant in most cases, and either $\mathrm{Ag}_{2} \mathrm{O}$ or $\mathrm{K}_{2} \mathrm{CO}_{3}$ as base depending on the arylated compound. Under these conditions, 
2-aryloxypyrimidines, ${ }^{81 \mathrm{a}} \mathrm{N}$-alkylacetanilides, ${ }^{81 \mathrm{~b}}$ cyclic enamides ${ }^{81 \mathrm{c}}$ and methyloximes ${ }^{81 \mathrm{~d}}$ have been successfully arylated (Figure 26). Finally, arylsilylethers have been utilized for Pd-catalyzed direct arylation of acetanilides. ${ }^{81 \mathrm{e}}$

\section{Figure 26}

Figure 26. Examples of arylation processes using boronic acids as aryl sources

In all the examples discussed up to here, the aryl fragment was prefunctionalized with an heteroatom (halogen, boron) or a functional group (peroxides). In some cases this additional functionality is not necessary, since a double oxidative coupling occurs. Sanford reported a Pd-catalyzed intermolecular oxidative C-C-coupling reaction for 2arylpyridine derivatives $\mathbf{5 5}$, employing oxone ${ }^{\circledR}$ as oxidant. ${ }^{82}$ The proposed mechanism is illustrated in Figure 27. The palladation of 55 affords cyclometallated 116. The subsequent step is its oxidation to a $\mathrm{Pd}^{\mathrm{IV}}$ complex 121. The critical step is a second cyclometallation of arylpiridine 55 promoted by the $\mathrm{Pd}^{\mathrm{IV}}$ center giving 122. Finally, the $\mathrm{C}-\mathrm{C}$ bond forming reductive elimination occurs to give homocoupled compound $\mathbf{1 2 3}$.

\section{Figure 27}

Figure 27. Proposed mechanism for the homocoupling of phenylpyridine

The same group has described other Pd-catalyzed oxidative cross-couplings of aromatic substrates. The reaction between $\mathrm{L} \sim \mathrm{C}-\mathrm{H}(\mathrm{L}=$ pyridine, pyrimidine, and pyrazole) and $\mathrm{Ar}-\mathrm{H}$, in combination with benzoquinone (BQ) employed as promoter and $\mathrm{Ag}_{2} \mathrm{CO}_{3}$ used as stoichiometric oxidant affords the corresponding bis-aryl products (Figure 28 left). ${ }^{83}$ When substituted aromatic substrates were investigated, the C-C coupling occurred at the less hindered position. Mechanistic studies suggest a reaction pathway that involves the following steps: (i) cyclometallation of benzo[ $h]$ quinoline 57 , (ii) $\mathrm{C}(\mathrm{Ar})-\mathrm{H}$ activation followed by $\mathrm{BQ}$-promoted $\mathrm{Ar}-\mathrm{Ar}^{\prime}$ reductive elimination to give the cross-coupled product 124, and (iii) oxidation of $\mathrm{Pd}^{0}$ to $\mathrm{Pd}^{\mathrm{II}}$ with $\mathrm{Ag}^{\mathrm{I}}{ }^{83 \mathrm{~b}}$ Analogous Pd-catalyzed cross-coupling reactions of arenes have been applied to $\mathrm{N}$-acetanilides, ${ }^{84 \mathrm{a}}$ pivalanilides, ${ }^{84 \mathrm{~b}}$ and ferrocenyl oxazolines, ${ }^{84 \mathrm{c}}$ among others (Figure 28 right).

\section{Figure 28}

Figure 28. Oxidative coupling of two different arylic fragments

Intramolecular versions of the arylation process have been widely used for the synthesis of polycyclic ring systems. Fagnou and co-workers described the synthesis of six-membered biaryl compounds from aryl bromides in combination with $\operatorname{Pd}(\mathrm{OAc})_{2}$, $\mathrm{K}_{2} \mathrm{CO}_{3}$ and 2-(diphenylphosphino)-2'-(N,N-dimethylamino)biphenyl 125 as ligand. ${ }^{85 a}$ From this initial observation the authors optimized a broad set of conditions using 
different palladium catalysts, aryl halides (including sterically encumbered aryl chlorides and bromides), bases, additives and solvents. ${ }^{85 \mathrm{~b}-\mathrm{d}}$ This group has been probably one of the most active in the field of arylation processes, in both intra- and intermolecular versions. Some specific reviews have appeared about this subject. ${ }^{85}$

\section{Figure 29}

Figure 29. Representative examples of intramolecular arylations

Echavarren et al have studied the regioselectivity observed in the intramolecular Pd-catalyzed arylation of substituted bromobenzyldiarylmethanes. ${ }^{86 a}$ (Figure 29, right). The reaction is favored by electron-withdrawing substituents on the aromatic ring, which is inconsistent with an $S_{E} A r$ mechanism. DFT calculations demonstrate that the Pd-catalyzed arylation proceeds by proton abstraction from the aryl ring promoted by carbonate or another base. ${ }^{86 \mathrm{~b}}$ This mechanistic proposal is in line with the results obtained by Fagnou. ${ }^{85}$ Larock et al reported the synthesis of substituted carbazoles, ${ }^{87 a}$ dibenzofurans and $^{87 b}$ fluoren-9-ones ${ }^{87 c}$ through a sequence Pd-migration/directed arylation. Many other examples of intramolecular arylation reactions through palladacycles have been reported during the last years. ${ }^{88}$ The vast amount of work developed precludes a detailed account here, but we expect that the general lines have been covered.

Finally, the Pd-catalyzed arylation of unactivated $\mathrm{Csp}^{3}-\mathrm{H}$ bond has been achieved using various methods. The arylation reaction with aryl iodides reported by diverse authors has been applied to substrates containing substituted pyridines, aminoquinolines, ${ }^{80 \mathrm{a}, 89 \mathrm{a}}$ or picolinamides $\mathbf{1 2 8},{ }^{80 \mathrm{a}}$ among others, as directing groups. In these transformations, $\mathrm{Pd}(\mathrm{OAc})_{2}$ was used as catalyst and $\mathrm{Ag}_{2} \mathrm{CO}_{3}$ or $\mathrm{AgOAc}$ were employed as oxidants (Figure 30 ). ${ }^{80 \mathrm{a}}$ The authors proposed a $\mathrm{Pd}^{\mathrm{II}} / \mathrm{Pd}^{\mathrm{IV}}$ mechanism. In addition, Fagnou has reported the synthesis of the natural products papaverine and crykonisine through Pd-catalyzed cross-coupling of $\mathrm{sp}^{3} \mathrm{C}-\mathrm{H}$ bond of picolines/azines Noxides $^{89 b, c}$ with aryl halides. The catalytic cycle proposed is based on a $\mathrm{Pd}^{0} / \mathrm{Pd}^{\mathrm{II}}$ mechanism. Arylboronic acids and esters have also been used for the arylation of $\beta-\mathrm{C}-\mathrm{H}$ bonds in O-methyl hydroxamic acids. ${ }^{89 \mathrm{~d}} \mathrm{Pd}(\mathrm{OAc})_{2}$ was used as the catalyst in combination with benzoquinone (additive), $\mathrm{Ag}_{2} \mathrm{O}$ or $\mathrm{Ag}_{2} \mathrm{CO}_{3}$ or air as oxidant and, in addition, the presence of base $\left(\mathrm{K}_{2} \mathrm{CO}_{3}\right.$ or $\left.\mathrm{K}_{2} \mathrm{HPO}_{4}\right)$ is required. Sanford has also described the construction a new $\mathrm{Csp}^{3}-\mathrm{Cp}^{2}$ bond in 8 -mehylquinoline substrate via $\mathrm{Pd}^{0 / I I}$-catalyzed reaction. ${ }^{82}$

\section{Figure 30}


Figure 30. Arylation of unactivated $\mathrm{Csp}^{3}-\mathrm{H}$ bonds

\section{7.- CARBON-CARBON BOND FORMATION: OTHER C-C COUPLINGS.}

We have seen that the formation of $\mathrm{C}-\mathrm{C}$ bonds through arylation is a wellestablished and developed process. Fortunately, this is not the only way to create new $\mathrm{C}-\mathrm{C}$ bonds. In this section we will describe some additional tools to introduce functional groups on the molecular skeleton, other than aryl fragments, with concomitant formation of new C-C bonds. The synthesis of carboxylic acids, esters, amides or other derivatives can be performed through carbonylation reactions, usually starting with the respective halo-compounds. Similar catalytic reactions using $\mathrm{C}-\mathrm{H}$ activations are still rare, but efforts have been reported. The synthesis of a number of bis-aryl ketones 131 using 130 and aldehydes as starting materials is carried out as shown in Figure 31. ${ }^{90 \mathrm{a}}$

\section{Figure 31}

Figure 31. Carbonylation without the use of $\mathrm{CO}$

This acylation is worthy of note since it uses air as oxidant, simplifying the experimental procedure and avoiding the use of more contaminant oxidants. In the same line, the introduction of the carbonyl group is achieved without the use of the very toxic $\mathrm{CO}$ reagent. The proposed reaction mechanism involves the initial directed orthopalladation of the aryl-containing substrate, followed by a migratory insertion of the $\mathrm{C}=\mathrm{O}$ bond into the metallated $\mathrm{Pd}-\mathrm{C}$ bond. The subsequent $\beta$-elimination produces the carbonylated derivative, while the metallic fragment undergoes a reductive elimination. Further oxidation of the $\operatorname{Pd}(0)$ species by oxygen regenerates the catalyst. ${ }^{90 a}$ An interesting contribution of Yu et al., ${ }^{90 \mathrm{~b}}$ also shown in Figure 31, uses DEAD (DEAD = $\mathrm{EtO}_{2} \mathrm{C}-\mathrm{N}=\mathrm{N}-\mathrm{CO}_{2} \mathrm{Et}$ ) coupled with inexpensive oxidants, such as oxone ${ }^{\circledR}$, as reagents for the catalytic introduction of the $\mathrm{CO}_{2}$ Et group. The outcome of the reaction is surprising since, instead of the expected C-N coupling, it affords carboxylic esters $\mathbf{1 3 2}$ from a large variety of substrates 130, like aryl-pyridines, pyrrolidinones or oximes. The mechanism seems to involve free radicals during the decomposition of the DEAD, since a decrease of the yield is observed in presence of radical scavengers. ${ }^{90 \mathrm{~b}}$

Although the introduction of carboxylate groups can be carried out using special reagents, the most usual method continues to be the reaction of the substrate with $\mathrm{CO}$ in presence of the adequate nucleophiles. This reaction presents some drawbacks, as the hazardous nature of the $\mathrm{CO}$ and its reducing power. Most of the work reported recently overcomes these problems and relevant processes have been developed. The synthesis of dicarboxylic acids $\mathbf{1 3 4}$ has been accomplished by $\mathrm{Yu}$ et al. ${ }^{91 \mathrm{a}}$ by carbonylation of 
arylic or vinylic carboxilates $\mathbf{1 3 3}$ with $\mathrm{CO}$ (1 atm) in presence of oxidants as $\mathrm{Ag}_{2} \mathrm{CO}_{3}$ (Figure 32). The carboxylate on the starting substrate orientates the incorporation of the incoming $\mathrm{CO}$, giving an anhydride intermediate, which is hydrolized to give $134 .{ }^{91 \mathrm{a}}$ The same concept has been used for the synthesis of anthranilic acids $\mathbf{1 3 5} .{ }^{91 \mathrm{~b}}$

\section{Figure 32}

Figure 32. Synthesis of functionalized carboxylic acids

In some cases the introduction of the $\mathrm{CO}$ fragment is followed by a second reaction, in a cascade process. The synthesis of isoquinolinones 136a (Figure 33) has been accomplished by $\mathrm{Pd}$-catalyzed reaction of methylene active compounds (for instance, ethyl-2-(2-iodophenyl)acetate) with lactams and CO. ${ }^{92 a}$ The first step is the formation of a palladacycle by oxidative addition, followed by $\mathrm{CO}$ insertion on the Pd$\mathrm{C}$ bond. The $\mathrm{N}$-bonding of the lactam and the reductive elimination by $\mathrm{C}-\mathrm{N}$ coupling regenerates the $\operatorname{Pd}(0)$ catalyst, while intramolecular aldol condensation on the resulting molecule gives 136a. ${ }^{92 a}$ The use of pyrazolidinones or oxazolidinones in the same synthetic sequence affords, respectively, $\mathbf{1 3 6}$ b and 136c, ${ }^{92 b}$ while coupling between diethyl-2-(2-iodophenyl) malonate, $\mathrm{N}$-(phenyl)benzimidoilchloride and $\mathrm{CO}$ gives isoquinolin-1(2H)-ones 136d. ${ }^{92 \mathrm{~d}}$

\section{Figure 33}

Figure 33 Synthesis of heterocycles by carbonylation

The cyanide group $\mathrm{CN}^{-}$, isoelectronic with $\mathrm{CO}$, can also be incorporated to organic skeletons through orthopalladated intermediates. The coupling between cyanide and arylic compounds can be a powerful alternative to the multi-step Sandmeyer synthesis of aromatic nitriles. ${ }^{93}$ Different arylpyridines $\mathbf{5 5}$ react with either $\mathrm{CuCN}^{93 a}$ or $\mathrm{K}_{3}\left[\mathrm{Fe}(\mathrm{CN})_{6}\right]{ }^{93 \mathrm{~b}}$ as cyanide sources, to give the corresponding nitriles, as shown in Figure 34. The proposed mechanism involves the orthopalladation of the arylpyridines 55 and transmetallation from the $\mathrm{CuCN}$ salt, the reductive elimination of $\mathbf{1 3 7}$ closing the catalytic cycle. ${ }^{93 a}$ In the case of the iron salt the mechanism is more complicated, since involves a cascade of bromination/cyanation steps. ${ }^{93 \mathrm{~b}}$ A critical point is that the use of $\mathrm{CuCN}$ or $\mathrm{K}_{3}\left[\mathrm{Fe}(\mathrm{CN})_{6}\right]$ keeps a very low concentration of cyanides in the reaction solution, avoiding the deactivation of the catalysts. The application of this reaction to the synthesis of natural products, as Luotonin A 138, has also been reported. ${ }^{93 \mathrm{c}}$

\section{Figure 34}

Figure 34. Cyanation processes. Application to the synthesis of natural products 
Alkynyl derivatives are versatile functional groups, and their introduction in organic skeletons through simple methods is still challenging. The most common synthetic protocol is the Sonogashira process, which uses prefunctionalized haloaryl derivatives, and palladium and copper as catalyst and cocatalyst, respectively. However, very few reports deal with the introduction of the alkynil fragment through a metalmediated $\mathrm{CH}$ bond activation. ${ }^{94}$ Some examples are shown in Figure 35 . In the case of heterocycles 139 the alkynylation is produced regioselectively at the $\alpha$-carbon with respect to the $\mathrm{N}$ atom, ${ }^{94 \mathrm{a}}$ without the assistance of an orthometallated derivative, while in the case of the acetanilides an orthopalladated intermediate is responsible of the ortho substitution in 140. ${ }^{94 \mathrm{~b}}$ The proposed mechanism for the synthesis of 140 involves insertion of the alkyne into the $\mathrm{Pd}-\mathrm{C}$ bond giving a Br-vinyl intermediate, which unusually $\beta$-eliminates a bromine atom generating the alkynyl derivative $\mathbf{1 4 0}$ and a bromide-Pd species. ${ }^{94 \mathrm{~b}}$

\section{Figure 35}

Figure 35. Alkynilation and synthesis of different heterocyles

The most usual reactivity of the alkynes towards orthopalladated complexes implies that, once the migratory insertion of the alkyne into the $\mathrm{Pd}-\mathrm{C}$ bond has occurred, an intramolecular cyclization takes place, giving different carbo- or heterocycles under catalytic or stoichiometric conditions. ${ }^{95}$ For instance, carbazoles 142 can be obtained catalytically from indoles 141, as shown in Figure 36. ${ }^{95 a, b}$ Indole-carboxylic acids $\mathbf{1 4 1 b}$ react under the same oxidative conditions to give the same type of heterocyles through a decarboxylative process. In a first step the carboxylate directs the palladation to the $\mathrm{C} 2$ position. Subsequent insertion of one molecule of alkyne and decarboxylation promotes the formation of a new palladacycle, which is able to insert a second molecule of alkyne. The reductive elimination by $\mathrm{C}-\mathrm{C}$ coupling produces $\mathbf{1 4 2}$. This process can be extended to benzofuran- and benzothiophene-carboxylic acids ( $X=O, S$; Figure 36), affording substituted dibenzofurans or dibenzothiophenes, albeit in lower yields.

\section{Figure 36}

Figure 36. Catalytic synthesis of carbo- and heterocycles from insertion of alkynes

The insertion of the alkyne can be a competing process with other alternative reaction pathways. A very remarkable selectivity has been found in the reactivity of the tethered indole derivatives $\mathbf{1 4 3}{ }^{95 \mathrm{c}}$ They react catalytically with internal alkynes (for instance, methyl but-2-ynoate) in presence of $\mathrm{PPh}_{3}$ and base, affording either the product of insertion 144 or the product of intramolecular cyclization 145 . It has been 
found that the orientation of the reaction can be directed by tunning of the base. The use of $\mathrm{CsOAc}$ drives the reaction to the exclusive formation of 145 , while the use of $\mathrm{NEt}_{3}$ affords chemoselectively $\mathbf{1 4 4}$. No details are given about the precise role of each base.

Stoichiometric versions of the insertion of alkynes into the $\mathrm{Pd}-\mathrm{C}$ bond of orthometallated complexes have been extensively used for the synthesis of heterocycles, as we have explained in the Introduction. To gain control of the number of inserted alkynes is a difficult task, and poly-insertion is usually observed. ${ }^{95 \mathrm{~d}, \mathrm{e}}$ As a rule of thumb, electron-poor alkynes usually produce mono-insertions, while electron-rich alkynes are more prone to promote two or three insertions. No more than three insertions have ever been observed. Recent reports of this type of reactions include the insertion of alkynes into biphenylamines ${ }^{95 \mathrm{~d}}$ or arylalkylamines. ${ }^{95 \mathrm{e}}$ Representative results are shown in Figure 37. Although in the present contributions the depalladation of $\mathbf{1 4 7}$ is not achieved, this strategy has been extensively developed during the 80-90's since it provided an alternative (albeit not totally general) access to isoquinolines. ${ }^{4,9}$

\section{Figure 37}

Figure 37. Stoichiometric synthesis of heterocycles from insertion of alkynes

Alkene ligands react with orthopalladated derivatives in a similar way to that described for alkynes. The first step is a migratory insertion of the alkene into the Pd-C bond. However, the second step is usually a $\beta$-elimination, resulting in the formation of substituted olefins. When the orthometallated fragment is an aryl group, the oxidative Heck coupling takes place giving arylated olefins. The processes shown in Figure 38 are examples of this methodology. ${ }^{96}$ In the first case (left) the olefination of the acetanilide 150 is produced in ortho to the $\mathrm{N}(\mathrm{H}) \mathrm{C}(\mathrm{O}) \mathrm{Me}$ fragment, resulting in the aryl-olefin 151, due to the directing effect of the oxygen to the less sterically hindered position on the palladated key-intermediate 152. The use of a mild oxidant as benzoquinone allows the process to be catalytic in $\mathrm{Pd}$. The orientation of the olefination, in some cases, can be governed through the presence of specific substituents, in addition to the already mentioned effect of the directing group. The silyl group $\mathrm{SiMe}_{3}$ is a nice example, as shown in Figure 38 (right). The acetanilide 153 undergoes regioselective alkenylation at the position occupied by the Si atom, giving the most hindered product 154 , due to the change of the palladation position at intermediate $\mathbf{1 5 5}{ }^{96 \mathrm{~b}}$

\section{Figure 38}

Figure 38. Representative alkenilations of arylic substrates 
Enantioselective alkenylations have been reported by the group of $\mathrm{Yu}$ et al. using prochiral substrates as diphenylacetic acids. ${ }^{97}$ The optimized chiral auxiliar ligand is the Boc-protected amino acid L-isoleucine. This amino acid chelates the Pd through the $\mathrm{N}$ and the $\mathrm{O}$ atoms driving the orthometallation of the diphenylacetate $\mathbf{1 5 6}$ at the $\mathrm{CH}$ activation step (Figure 39). Chiral complex 157 reacts with different styrenes affording desymmetrized alkenylated 158 with excellent ee values and high yields.

\section{Figure 39}

Figure 39. Enantioselective desymmetrizations through alkenylations

It is remarkable that some examples of ortho-alkenylation have been reported in molecules without directing groups or, at least, without coordinating atoms that can promote a chelation. Even if orthopalladation is not involved, they merit to be mentioned here due to their practical importance. The discrimination in these cases is achieved through stereoelectronic control: ${ }^{98}$ that is, the introduction of groups that either electronically or sterically blocks or direct the $\mathrm{C}-\mathrm{H}$ bond activation to a given position. Typical examples are N-substituted pyrroles. In the case of small N-R groups the $\mathrm{CH}$ activation is directed to the natural $\mathrm{C} 2$ site, while bulky $\mathrm{N}$-substituents blocks the $\mathrm{C} 2$ position and favours selectively the C3 site. ${ }^{98 \mathrm{a}}$ The same concepts have been applied to the alkenylation of other types of substrates, such as pyridine N-oxides. ${ }^{98 \mathrm{~b}}$

The alkenylation of heterocycles is not limited to simple olefins (acrylate or styrene), since dienes (butadiene) ${ }^{99}$ can also be functionalized. Stoichiometric reactivity have been studied by Vicente et al. using maleate and fumarate esters. ${ }^{100 a}$ The insertion of these alkenes into the $\mathrm{Pd}-\mathrm{C}$ bond of aryl complexes 159 gives the corresponding $\sigma$ alkyl complexes $\mathbf{1 6 0}$ or $\mathbf{1 6 1}$, which are stable due to the locked conformation of the resulting palladacycle. Both reactions occur stereoselectively (Figure 40): the insertion of maleate affords only one of the possible diastereoisomers of $160(R R / S S)$ while the insertion of fumarate affords the $(R S / S R)$ diastereoisomer of $161 .^{100 a}$

\section{Figure 40}

Figure 40. Stoichiometric alkenylations

The same group has studied the stoichiometric insertion of small unsaturated molecules into a Pd-C carbon bond. These studies cover a wide prospect of substrates, as carbodiimides, isothiocyanates, nitriles, CO or cyanamides. ${ }^{100 b, c}$ Some representative examples 162-164 are shown in Figure $41 .^{100 \mathrm{~b}}$ In some cases, depalladation has been achieved and interesting heterocycles, as lactam 165, can be isolated. ${ }^{100 \mathrm{c}}$

\section{Figure 41}


Figure 41. Insertion of different small unsaturated molecules

All examples reported up to now in this section involves reagents containing unsaturated carbons $(\mathrm{C} \equiv \mathrm{O}, \mathrm{C} \equiv \mathrm{N}, \mathrm{C} \equiv \mathrm{C}, \mathrm{C}=\mathrm{C})$, that is, $\mathrm{Csp}$ or $\mathrm{Csp}^{2}$ atoms. The alkylation process implies the coupling with $\mathrm{Csp}^{3}$ carbons, and it is somewhat more difficult. Significant advances have been reported by the group of $\mathrm{Yu}$ et al, using transmetallation reactions from tin or boron reagents. ${ }^{101}$ The first example of Pd-catalyzed methylation of arylic Csp ${ }^{2}-\mathrm{H}$ bonds is illustrated in Figure 42, and is based on the transmetallation of a methyl fragment from $\mathrm{SnMe}_{4}$ (batch-wise added) to a $\mathrm{Pd}(\mathrm{II})$ orthometallated complex 166. The reaction needs an oxidant to become catalytic and mono- (167) and dimethylated (168) compounds are obtained. ${ }^{101 a}$ The method is valid for a range of $\mathrm{SnR}_{4}$ reagents and overcomes the homocoupling reaction. Further improvement of this reaction is based on boron reagents. The use of methylboroxine ${ }^{101 b}$ or other boron reagents ${ }^{101 c-e}$ allows for the functionalization of $\mathrm{Csp}^{3}$ substrates (allowing the $\mathrm{Csp}^{3}-\mathrm{Csp}^{3}$ coupling), tolerating the presence of functional groups and avoiding the toxicity of tin reagents. Some examples of this noteworthy chemistry are given in Figure 42. For instance, alkyl pyridines or quinolines 169 can be alkylated to give derivatives $\mathbf{1 7 2},{ }^{101 \mathrm{~b}}$ carboxylic acids 170 react cleanly with different borates $\mathrm{RB}(\mathrm{OH})_{2}$ affording modified acids $\mathbf{1 7 3}^{101 \mathrm{c}, \mathrm{d}}$ and even hydroxamic acids $\mathbf{1 7 1}$ can be alkylated selectively to provide species 174. ${ }^{101 \mathrm{e}}$

\section{Figure 42}

Figure 42. Different Pd-catalyzed methylation processes from B- and Sn-reagents CONCLUSION. We have shown how orthopalladation is a powerful synthetic tool for the formation of new C-O, C-N, C-X and C-C bonds, using different strategies as the oxidative coupling or the migratory insertion. Moreover, the directing effect displayed by the auxiliary groups promotes regioselective reactions. During the last 5 years significant advances have been produced in this area, conceptually (using new ideas) and experimentally (new substrates, oxidants, applications, and so on). It is clear that the work in this area is not finished at all, and that it should be desirable to test more substrates, directing groups, reagents and oxidants, in order to obtain access to widest scope of families of compounds.

ACKNOWLEDGMENT. The authors thank the MICINN (Spain, Project CTQ200801784) and Gobierno de Aragón (Spain, Project PI071/09) for financial support. L. C. thanks MICINN for a Juan de la Cierva grant, S. N. thanks Consejo Superior de Investigaciones Científicas (Spain) for a JAE-Doc contract and E. S. thanks Gobierno 
de Aragón and Consejo Superior de Investigaciones Científicas for a postdoctoral contract.

\section{REFERENCES}

[1] Transition Metal Organometallics in Organic Synthesis, volumes 10 (Ojima, I. Ed.) and 11 (Hiyama, T. Ed.) of Comprehensive Organometallic Chemistry III (Crabtree, R. H.; Mingos, M. P. Editors-in-Chief), Elsevier Science, Amsterdam, The Netherlands, 2007.

[2] Handbook of Organopalladium Chemistry for Organic Synthesis, Negishi, E. Editor, Wiley-Interscience, John Wiley and Sons, New York, USA, 2002.

[3] (a) Tsuji, J. Palladium Reagents and Catalysts: Innovations in Organic Synthesis; Wiley, Chichester, U.K., 1995. (b) Tsuji, J. Palladium Reagents and Catalysts: New Perspectives for the 21st Century, John Wiley\&Sons, Chichester, U.K. 2004.

[4] Dupont, J.; Pfeffer, M., Palladacycles, Wiley-VCH, Weinheim, Germany, 2008.

[5] Selected reviews: (a) Dupont, J.; Pfeffer, M.; Spencer, J. Eur. J. Inorg. Chem. 2001, 1917. (b) Kakiuchi, F.; Murai, S. Acc. Chem. Res. 2002, 35, 826. (c) Kakiuchi, F.; Chatani, N. Adv. Synth. Catal. 2003, 345, 1077. (d) Bedford, R. B. Chem. Commun. 2003, 1787. (e) van der Boom, M. E.; Milstein, D. Chem. Rev. 2003, 103, 1759. (f) Omae, I. Coord. Chem. Rev. 2004, 248, 995. (g) Farina, V. Adv. Synth. Catal. 2004, 346, 1553. (h) Beletskaya, I. P.; Cheprakov, A. V. J. Organomet. Chem. 2004, 689, 4055. (i) Dupont, J.; Consorti, C. S.; Spencer, J., Chem. Rev. 2005, 105, 2527. (j) Dunina, V. V.; Gorunova, O. N.; Russ.Chem. Rev. 2005, 74, 871 .

[6] Takahashi, H.; Tsuji, J., J. Organomet. Chem. 1967, 10, 511.

[7] (a) Thompson, J. M.; Heck, R. F., J. Org. Chem. 1975, 40, 2667. (b) Dupont , J.; Pfeffer, M.; Daran , J. C.; Jeannin, Y. Organometallics, 1987, 6, 899.

[8] (a) Yamamoto, Y.; Yamazaki, H., Inorg. Chim. Acta, 1980, 41, 229. (b) Vicente, J.; Saura-Llamas, I.; Grunwald, C.; Alcaraz, C.; Jones, P. G.; Bautista, D. Organometallics 2002, 21, 358. (c) O’Sullivan, R. D.; Parkins, A. W. J. Chem. Soc., Chem. Commun. 1984, 1165.

[9] (a) Ryabov, A. D. Synthesis 1985, 233. (b) Bahsoun, A.; Dehand, J.; Pfeffer, M.; Zinsius, M., J. Chem. Soc., Dalton Trans. 1979, 547. (c) Massarani, F.; Pfeffer, M.; Le Borgne, G., Organometallics 1987, 6, 2029. (d) Pfeffer, M. Pure Appl. Chem. 1992, 64, 335. (e) Massarani, F.; Pfeffer, M.; Le Borgne, G., Organometallics 1987, 6, 2043. (f) Pfeffer, M.; Rotteveel, M. A., J. Org. Chem. 
1992, 57, 2147. (g) Tao, W.; Silverberg, L. J.; Rheingold, A. L.; Heck, R. F. Organometallics 1989, 8, 2550. (h) Larock, R. C.; Doty, M. J.; Cacchi, S. J. Org. Chem. 1993, 58, 4579. (i) Pfeffer, M.; Rotteveel, M. A.; Le Borgne G.; Fischer, J. J. Org.Chem. 1992, 57, 2147. (j) Ossor, H.; Pfeffer, M.; Jastrzebski, J. T. B. H.; Stam, C. H. Inorg.Chem. 1987, 26, 1169.

[10] (a) Girling, I. R.; Widdowson, D. A., Tetrahedron Lett. 1982, 23,1957. (b) Horino, H.; Inoue, N., Tetrahedron Lett. 1979, 26, 2403. (c) Chao, C. H.; Hart, D. W.; Bau, R.; Heck, R. F., J. Organomet. Chem. 1979, 179, 301. (d) Girling, I. R.; Widdowson, D. A., Tetrahedron Lett. 1982, 23, 4281. (e) Barr, N.; Dyke, S. F.; Quessy, S. N., J. Organomet. Chem.1983, 253, 391.

[11] (a) Diederen, J. J. H.; Fruhauf, H. W.; Hiemstra, H.; Vrieze, K.; Pfeffer, M. Tetrahedron Lett. 1998, 39, 4111. See more recent work at: (b) Chengebroyen, J.; Linke, M.; Robitzer, M.; Sirlin, C.; Pfeffer, M. J. Organomet. Chem. 2003, 687, 313. (c) Sirlin, C.; Chengebroyen, J.; Konrath, R.; Ebeling, G.; Raad, I.; Dupont, J.; Paschaki, M.; Kotzyba-Hilbert, F.; Harf-Monteil, C.; Pfeffer, M. Eur. J. Org. Chem. 2004, 1724.

[12] (a) Allison, J. A. C.; El Khadem, H. S.; Wilson, C. A. J., Heterocyclic Chem. 1975, 12, 1275. (b) Horino, H.; Inoue, N., J. Org. Chem. 1981, 46, 4416. (c) Kasahara, A.; Izumi, T.; Maemura, M. Bull. Chem. Soc. Jpn. 1977, 50, 1878. (d) Onishi, M.; Hiraki, K.; Iwamoto, A., J. Organomet. Chem. 1984, 262, C11.

[13] (a) Holton, R. A.; Natalie, K. J., Tetrahedron Lett. 1981, 22, 267. (b) Clark, P. W.; Dyke, H. J.; Dyke, S. F.; Perry, G. J. Organomet. Chem, 1983, 253, 399.

[14] (a) Lewis, L. N. J. Am. Chem. Soc. 1986, 108, 743. (b) Santra, P. K.; Saha, C. R. J. Mol. Catal. 1987, 39, 279. (c) Bose, A.; Saha, C. R. J. Mol. Catal. 1989, 49, 271.

[15] (a) Beller, M.; Fischer, H.; Herrmann, W. A.; Ofele, K.; Brossmer, C. Angew. Chem., Int. Ed. Engl. 1995, 34, 1848. (b) Albisson, D. A.; Bedford, R. B.; Lawrence, S. E.; Scully, P. N., Chem. Commun. 1998, 2095. (c) Alacid, E.; Nájera, C., Adv. Synth. Catal. 2006, 348, 2085. (d) Schnyder, A.; Indolese, A. F.; Studer, M.; Blaser, H.-U., Angew. Chem. 2002, 41, 3668.

[18] This volume has appeared during the elaboration of this manuscript. Selected contributions dedicated to palladacycles: (a) Lyons, T. W.; Sanford, M. S. Chem. Rev. 2010, 110, 1147 (Pd-catalytic processes). (b) Albrecht, M. Chem. Rev. 2010, 110, 576 (methods to prepare cyclometallated complexes, in general). 
[19] Butter, A.; Walker, J. V. Chem. Rev. 1993, 93, 1937.

[20] Metal Catalyzed Cross Coupling Reactions. Dieterich, F.; Stang, P. J. Eds. WileyVCH: New York, NY, 1998.

[21] Sotomayor, N.; Lete, E. Curr. Org. Chem. 2003, 7, 275.

[22] Silverman, G. S.; Rakita, P. E. Eds. Handbook of Grignard Reagents. Dekker: New York, NY, 1996.

[23] (a) Ryabov, A. D. Chem. Rev. 1985, 3, 233-252. (b) Reference 4, Chapter 5.

[24] (a) Vicente, J.; Saura-Llamas, I.; Bautista D. Organometallics. 2005, 24, 6001. (b) Vicente, J.; Saura-Llamas, I.; García-López; J.-A.; Calmuschi-Cula, B. Organometallics. 2007, 26, 2768. (c) Nieto, S.; Arnau, P.; Serrano, E.; Navarro, R.; Soler, T.; Cativiela, C.; Urriolabeitia, E. P. Inorg. Chem. 2009, 48, 11963.

[25] Giri, R.; Chen, X.; Yu, J.-Q. Angew. Chem. Int. Ed. 2005, 44, 2112.

[26] Mei, T.-S.; Giri, R.; Maugel, N.; Yu, J.-Q. Angew. Chem. Int. Ed. 2008, 47, 5215.

[27] Koval, V. I. Russ. J. Org. Chem. 2002, 38, 301.

[28] Kalyani, D.; Dick. R. A.; Anani, Q. W.; Sanford, M. S. Tetrahedron 2006, 62, 11483.

[29] Kalyani, D.; Dick. R. A.; Anani, Q. W.; Sanford, M. S. Org. Lett. 2006, 8, 2523.

[30] Wan, X.; Ma, Z.; Li, B.; Zhang, K.; Cao, S.; Zhang, S.; Shi, Z. J. Am. Chem. Soc. 2006, 128, 7416.

[31] Zhao, X.; Dimitrijevic, E.; Dong, V. M. J. Am. Chem. Soc. 2009, 131, 3466.

[32] Kakiuchi, F.; Kochi, T.; Mutsutani, H.; Kobayashi, N.; Urano, S.; Sato, M.; Nishiyama, S.; Tanabe, T. J. Am. Chem. Soc. 2009, 131, 11310.

[33] Deprez; N. R., Sanford, M. S. Inorg. Chem. 2007, 46, 1924.

[34] (a) Whitfield, S. R.; Sanford, M.S. J. Am. Chem. Soc 2007, 129, 15142. (b) Powers, D. C.; Ritter, T. Nat. Chem. 2009, 1, 302. (c) Arnold, P. L.; Sanford, M.S.; Pearson, S. M. J. Am. Chem. Soc 2009, 131, 13912. (d) Canty, A. J. Dalton Trans. 2009, 10409.

[35] Wang, X.; Mei, T.-S.; Yu, J.-Q. J. Am. Chem. Soc 2009, 131, 7520.

[36] (a) Hull, L. K.; Anani, W. Q.; Sanford, M. S. J. Am. Chem. Soc 2006, 128, 7134. (b) Furuya, T.; Ritter, T. J. Am. Chem. Soc. 2008, 130, 10060. (c) Ball, N. D.; Sanford, M. S. J. Am. Chem. Soc. 2009, 131, 3796.

[37] Periana, R. A.; Taube, D. J.; Gamble, S.; Taube, H.; Satoh, T.; Fujii, H. Science 1998, 280, 560.

[38] Dick, A. R.; Hull, K. L.; Sanford, M. S. J. Am. Chem. Soc. 2004, 126, 2300. 
[39] (a) Kalyani, D.; Sanford, M. S. Org. Lett. 2005, 7, 4149. (b) Desai, L. V.; Malik, H. A.; Sanford, M. S. Org. Lett. 2006, 8, 1141.

[40] Gou, F.-R.; Wang, X.-C.; Huo, P.-F.; Bi, H.-P.; Guan, Z.-H.; Liang, Y.-M. Org. Lett. 2009, 11, 5726.

[41] Desai, L. V.; Hull, K. L.; Sanford, M. S. J. Am. Chem. Soc. 2004, 126, 9542.

[42] Kalberer, E. W.; Whitfield, S. R.; Sanford, M. S. J. Mol. Catal., A. 2006, 251, 108.

[43] Wang, D.-H.; Hao, X.-S.; Wu, D.-F.; Yu, J.-Q. Org. Lett. 2006, 8, 3387.

[44] Wang, G.-W.; Yuan, T.-T.; Wu, X.-L. J. Org. Chem. 2008, 73, 4717.

[45] Reddy, B. V. S.; Reddy, L. R.; Corey, E. J. Org. Lett. 2006, 8, 3391.

[46] Giri, R.; Liang, J.; Lei, J.-G.; Li, J.-J.; Wang, D.-H-; Chen, X.; Naggar, I. C.; Guo, C.; Foxman, B. M.; Yu, J.-Q. Angew. Chem. Int. Ed. 2005, 44, 7420.

[47] Zhang, J.; Khaskin, E.; Anderson, N. P.; Zavalij, P.Y. Vedernikov, A. N. Chem. Commun. 2008, 5529.

[48] Zhang, Y.-H.; Yu, J.-Q. J. Am. Chem. Soc. 2009, 131, 14654.

[49] a) Dick, A. R.; Kampf, J. W.; Sanford, M. S. J. Am. Chem. Soc. 2005, 127, 12790.

b) Racowski, J. M.; Dick, A. R.; Sanford, M. S. J. Am. Chem. Soc. 2009, 131, 10974.

[50] Powers, D. C.; Geibel, M. A. L.; Klein, J. E. M. N.; Ritter, T. J. Am. Chem. Soc. 2009, 131, 17050 .

[51] Relevant reviews: (a) Müller, P.; Fruit, C. Chem. Rev. 2003, 103, 2905. (b) Dick, A. R.; Sanford, M. S. Tetrahedron 2006, 62, 2439. (c) Herrerias, C. I.; Yao, X.; Li, C. J. Chem. Rev. 2007, 107, 2546. (d) Davies, H.; M. L. Manning, J. R. Nature 2008, $451,417$.

[52] (a) Brown, E. G. Ring Nitrogen and Key Biomolecules; Kluwer: Boston MA, 1998. (b) Eds. Li, J.-J.; Corey, E. J. Name Reactions in Heterocyclic Chemistry; Wiley-Interscience: Hoboken, NJ, 2005.

[53] Thu, H.-Y.; Yu, W.-Y.; Che, C.-M. J. Am. Chem. Soc. 2006, 128, 9048.

[54] Dick, A. R.; Reny, M. S.; Kampf, J. W.; Sanford, M. S. Organometallics 2007, 26,1365 .

[55] Tsang, P. W. C.; Zheng, N.; Buchwald, S. L. J. Am. Chem. Soc. 2005, 127, 14560.

[56] Jordan-Hore, J. A.; Johanson, C.C.C.; Gulias, M.; Beck, E. M.; Gaunt, M. J. J. Am. Chem. Soc. 2008, 130, 16184.

[57] Li, J.-J.; Mei, T.-S.; Yu, J.-Q. Angew. Chem. Int. Ed. 2008, 47, 6452. 
[58] Mei, T.-S.; Wang, X., Yu, J.-Q. J. Am. Chem. Soc. 2009, 131, 10806.

[59] Neumann, J. J.; Rakshit, S.; Dröge, T.; Glorius, F. Angew. Chem. Int. Ed. 2009, 48,1 .

[60] Wasa, M.; Yu, J.-Q. J. Am. Chem. Soc. 2008, 130, 14058.

[61] Xiao, Q.; Wang, W.-H.; Liu, G.; Meng, F.-K.; Chen, J.-H.; Yang, Z. Shi, Z.-J. Chem. Eur. J. 2009, 15, 7292.

[62] Zhao, T.; Xu, B. Org. Lett. 2010, 12, 212.

[63] Muñiz, K. J. Am. Chem. Soc. 2007, 129, 14542.

[64] Ke, Z.; Cundari, T. R. Organometallics. 2010, 29, 821.

[65] Spencer, J.; Pfeffer, M.; DeCian, A.; Fischer, J. J. Org. Chem. 1995, 60, 1005.

[66] (a) Inamoto, K.; Arai, Y.; Hiroya, K.; Doi, T. Chem Commun. 2008, 5529. (b) Joyce, L. L.; Batey, R. A. Org. Lett. 2009, 11, 2792.

[67] Yadav, A. K.; Ila, H.; Junjappa, H. Eur. J. Org. Chem. 2010, 338.

[68] Zhao, X.; Dimitrijevic, E.; Dong V. M. J. Am. Chem. Soc. 2009, 131, 3466.

[69] Stepanova, V. A.; Dunina, V. V.; Smoliakova, I. P. Organometallics 2009, 28, 6546.

[70] Metal-Catalyzed Cross-Coupling Reactions; de Meijere, A.; Diederich, F. Eds; Wiley-VCH: Weinheim, Germany, 2004.

[71] Alberico, D.; Scott, E.; Lautens, M. Chem. Rev. 2007, 107, 174.

[72] (a) Catellani, M. Handbook of Organopalladium Chemistry for Organic Synthesis; Negishi, E.-I.; de Mejiere, A. Eds.; John Wiley\&Sons: Hoboken, N. J., 2002. (b) Catellani, M. Handbook of C-H Transformations; Dyker, G. Ed; WileyVCH: Weinheim, Germany, 2005. (c) Catellani, M. Top. Organomet. Chem. 2005, 14, 21.

[73] (a) Maestri, G.; Della Ca, N.; Catellani, M. Chem. Commun. 2009, 4892. (b) Della Ca, N.; Maestri, G.; Catellani, M. Chem. Eur. J. 2009, 15, 7850 (c) Catellani, M.; Motti, E.; Della Ca, N. Acc. Chem. Res. 2008, 41, 1512.

[74] (a) Kalyani, D.; Deprez, N. R.; Desai, L. V.; Sanford, M. S. J. Am. Chem. Soc. 2005, 127, 7330. (b) Deprez, N. R.; Sanford, M. S. Inorg. Chem. 2007, 46, 1924.

[75] (a) Shabashov, D.; Daugulis, O. J. Org. Chem. 2007, 72, 7720. (b) Spencer, J.; Chowdhry, B. Z.; Mallet, A. I.; Rathnam, R. P.; Adatia, T.; Bashall, A.; Rominger, F. Tetrahedron 2008, 64, 6082.

[76] Deprez, N. R.; Sanford, M. S. J. Am. Chem. Soc. 2009, 131, 11234. 
[77] Cotton, F. A.; Koshevoy, I. O.; Lahuerta, P.; Murillo, C. A.; Sanau, M.; Ubeda, M. A.; Zhao, Q. J. Am. Chem. Soc. 2006, 128, 13674.

[78] Yu, W.-Y.; Nga Sit, W.; Zhou, Z.; Chan, A. S.-C. Org. Lett. 2009, 11, 3174.

[79] (a) Daugulis, O.; Do, H.-Q.; Shabashov, D. Acc. Chem. Res. 2009, 42, 1074. (b) Yang, F.; Wu, Y.; Li, Y.; Wang, B.; Zhang, J. Tetrahedron 2009, 65, 914.

[80] (a) Zaitsev, V. G.; Shabashov, D.; Daugulis, O. J. Am. Chem. Soc. 2005, 13154. (b) Shabashov, D.; Daugulis, O. Org. Lett. 2006, 8, 4947. (c) Lazareva, A.; Daugulis, O. Org. Lett. 2006, 8, 5211. (d) Chiong, H. A.; Pham, Q.-N.; Daugulis, O. J. Am. Chem. Soc. 2007, 129, 9879. (e) Shabashov, D.; Molina Maldonado, J. R.; Daugulis, O. J. Org. Chem. 2008, 73, 7818. (f) Campeau, L.-C.; Parisien, M.; Jean, M.; Fagnou, K. J. Am. Chem. Soc. 2006, 128, 581. (g) Gürbüz, N.; Özdemir, I.; Çetinkaya, B. Tetrahedron Lett. 2005, 46, 2273.

[81] (a) Gu, S.; Chen, C.; Chen, W. J. Org. Chem. 2009, 74, 7203. (b) Shi, Z.; Li, B.; Wan, X.; Chen, J.; Fang, Z.; Cao, B.; Qin, C.; Wang, Y. Angew. Chem. Int. Ed. 2007, 46, 5554. (c) Zhou, H.; Xu, Y.-H.; Chung, W.-J.; Loh, T.-P. Angew. Chem. Int. Ed. 2009, 48, 5355. (d) Sun, C.-L.; Liu, N.; Li, B.-J.; Yu, D.-G.; Wang, Y.; Shi, Z.-J. Org. Lett. 2009, 12, 184. (e) Yang, S.; Li, B.; Wan, X.; Shi, Z. J. Am. Chem. Soc. 2007, 129, 6066.

[82] Hull, K. L.; Lanni, E. L.; Sanford, M. S. J. Am. Chem. Soc. 2006, 128, 14047.

[83] (a) Hull, K. L.; Sanford, M. S. J. Am. Chem. Soc. 2007, 129, 11904. (b) Hull, K. L.; Sanford, M. S. J. Am. Chem. Soc. 2009, 131, 9651.

[84] (a) Li, B.-J.; Tian, S.-L.; Fang, Z.; Shi, Z.-J. Angew. Chem. Int. Ed. 2008, 47, 1115. (b) Brasche, G.; García-Fortanet, J.; Buchwald, S. L. Org. Lett. 2008, 10, 2207. (c) Xia, J.-B.; You, S.-L. Organometallics 2007, 26, 4869.

[85] (a) Campeau, L.-C.; Parisien, M.; Leblanck, M.; Fagnou, K. J. Am. Chem. Soc., 2004, 126, 9186. (b) Campeau, L.-C.; Thansandote, P.; Fagnou, K. Org. Lett. 2005, 7, 1857. (c) Lafrance, M.; Blaquière, N.; Fagnou, K. Eur. J. Org. Chem. 2007, 5, 811. (d) Lafrance, M.; Lapointe, D.; Fagnou, K. Tetrahedron 2008, 64, 6015. (e) review: Liégault, B.; Lee, D.; Huestis, M. P.; Stuart, D. R.; Fagnou, K. J. Org. Chem. 2008, 73, 5022.

[86] (a) Pascual, S.; de Mendoza, P.; Echavarren, A. M. Org. Biomol. Chem. 2007, 5, 2727. (b) García-Cuadrado, D.; de Mendoza, P.; Braga, A. A. C.; Maseras, F.; Echavarren, A. M. J. Am. Chem. Soc. 2007, 129, 6880. 
[87] (a) Zhao, J.; Larock, R. C. Org. Lett. 2005, 7, 701. (b) Zhao, J.; Larock, R. C. J. Org. Chem. 2006, 71, 5340. (c) Zhao, J.; Yue, D.; Campo, M. A.; Larock, R. C. J. Am. Chem. Soc. 2007, 129, 5288.

[88] (a) Kim, G.; H., K. J.; Lee, K. Y. J. Org. Chem. 2006, 71, 2185. (b) Taylor, S. R.; Ung, A. T.; Pyne, S. G. Tetrahedron 2007, 63, 10889. (c) Watanabe, T.; Oishi, S.; Fujii, N.; Ohno, H. J. Org. Chem. 2009, 74, 4720. (d) Hernández, S.; Moreno, I.; SanMartín, R.; Gómez, G.; Herrero, M. T.; Domínguez, E. J. Org. Chem. 2010, $75,434$.

[89] (a) Reddy, B. V. S.; Reddy, L. R.; Corey, E. J. Org. Lett. 2006, 8, 3391. (b) Brasche, G.; García-Fortanet, J.; Buchwald, S. L. Org. Lett. 2008, 10, 2207. (c) Schipper, D. J.; Campeau, L.-C.; Fagnou, K. Tetrahedron 2009, 65, 3155. (d) Wang, D.-H.; Wasa, M.; Giri, R.; Yu, J.-Q. J. Am. Chem. Soc. 2008, 130, 7190.

[90] (a) Jia, X.; Zhang, S.; Wang, W.; Luo, F.; Cheng, J. Org. Lett. 2009, 11, 3120. (b) Yu, W.-Y.; Sit, W. N.; Lai, K.-M.; Zhou, Z.; Chan, A. S. C. J. Am. Chem. Soc. 2008, 130, 3304.

[91] (a) Giri, R.; Yu, J.-Q. J. Am. Chem. Soc. 2008, 130, 14082. (b) Giri, R.; Lam, J. K.; Yu, J.-Q. J. Am. Chem. Soc. 2010, 132, 686.

[92] (a) Chouhan, G.; Alper, H. Org. Lett. 2008, 10, 4987. (b) Chouhan, G.; Alper, H. J. Org. Chem. 2009, 74, 6181. (c) Zheng, Z.; Alper, H. Org. Lett. 2008, 10, 4903.

[93] (a) Jia, X.; Yang, D.; Zhang, S.; Cheng, J. Org. Lett. 2009, 11, 4716. (b) Jia, X.; Yang, D.; Wang, W.; Luo, F.; Cheng, J. J. Org. Chem. 2009, 74, 9470. (c) Ju, Y.; Liu, F.; Li, C. Org. Lett. 2009, 11, 3582.

[94] (a) Tobisu, M.; Ano, Y.; Chatani, N. Org. Lett. 2009, 11, 3250. (b) Seregin, I. V.; Ryabova, V.; Gevorgyan, V. J. Am. Chem. Soc. 2007, 129, 7742.

[95] (a) Yamashita, M.; Horiguchi, H.; Hirano, K.; Satoh, T.; Miura, M. J. Org. Chem. 2009, 74, 7481. (b) Yamashita, M.; Hirano, K.; Satoh, T.; Miura, M. Org. Lett. 2009, 11, 2337. (c) Chernyak, N.; Tilly, D.; Li, Z.; Gevorgyan, V. Chem. Commun. 2010, 46, 150. (d) Albert, J.; D’Andrea, L.; Granell, J.; Zafrilla, J.; Font-Bardia, M.; Solans, X. J. Organomet. Chem. 2007, 692, 4895. (e) Vicente, J.; Saura-Llamas, I.; Turpín, J.; Bautista, D.; Ramírez de Arellano, M. C.; Jones, P. G. Organometallics 2009, 28, 4175 and references cited therein.

[96] (a) Lee, G. T.; Jiang, X.; Prasad, K.; Repic, O.; Blacklock, T. J. Adv. Synth. Catal. 2005, 347, 1921. (b) Rauf, W.; Thompson, A. L.; Brown, J. M. Chem. Commun. 2009, 3874. 
[97] Shi, B.-F.; Zhang, Y.-H.; Lam, J. K.; Wang, D.-H.; Yu, J.-Q. J. Am. Chem. Soc. 2010, 132, 460.

[98] (a) Beck, E. M.; Grimster, N. P.; Hatley, R.; Gaunt, M. J. J. Am. Chem. Soc. 2006, 128, 2528. (b) Wu, J.; Cui, X.; Chen, L.; Jiang, G.; Wu, Y. J. Am. Chem. Soc. 2009, 131, 13888.

[99] Houlden, C. E.; Bailey, C. D.; Ford, J. G.; Gagné, M. R.; Lloyd-Jones, G. C.; Booker-Milburn, K. I. J. Am. Chem. Soc. 2008, 130, 10066.

[100] (a) Vicente, J.; Abad, J. A.; López-Sáez, M. J.; Jones, P. G. Organometallics 2010, 29, 409. (b) Vicente, J.; Abad, J. A.; López-Sáez, M. J.; Jones, P. G.; Bautista, D. Chem. Eur. J. 2010, 16, 661. (c) Vicente, J.; Saura-Llamas, I.; García-López, J. A.; Bautista, D. Organometallics 2009, 28, 448.

[101] (a) Chen, X.; Li, J.-J.; Hao, X.-S.; Goodhue, C. E.; Yu, J.-Q. J. Am. Chem. Soc. 2006, 128, 78. (b) Chen, X.; Goodhue, C. E.; Yu, J.-Q. J. Am. Chem. Soc. 2006, 128, 12634. (c) Giri, R.; Maugel, N.; Li, J.-J.; Wang, D.-H.; Breazzano, S. P.; Saunders, L. B.; Yu, J.-Q. J. Am. Chem. Soc. 2007, 129, 3510. (d) Wang, D.-H.; Mei, T.-S.; Yu, J.-Q. J. Am. Chem. Soc. 2008, 130, 17676. (e) Wang, D.-H.; Wasa, M.; Giri, R.; Yu, J.-Q. J. Am. Chem. Soc. 2008, 130, 7190. 